\title{
WestVirginiaUniversity
}

THE RESEARCH REPOSITORY @ WVU

Graduate Theses, Dissertations, and Problem Reports

2012

\section{Age, Expertise, and the Sunk-Cost Fallacy}

Tara E. Karns

West Virginia University

Follow this and additional works at: https://researchrepository.wvu.edu/etd

\section{Recommended Citation}

Karns, Tara E., "Age, Expertise, and the Sunk-Cost Fallacy" (2012). Graduate Theses, Dissertations, and Problem Reports. 3486.

https://researchrepository.wvu.edu/etd/3486

This Thesis is protected by copyright and/or related rights. It has been brought to you by the The Research Repository @ WVU with permission from the rights-holder(s). You are free to use this Thesis in any way that is permitted by the copyright and related rights legislation that applies to your use. For other uses you must obtain permission from the rights-holder(s) directly, unless additional rights are indicated by a Creative Commons license in the record and/ or on the work itself. This Thesis has been accepted for inclusion in WVU Graduate Theses, Dissertations, and Problem Reports collection by an authorized administrator of The Research Repository @ WVU. For more information, please contact researchrepository@mail.wvu.edu. 
Age, Expertise, and the Sunk-Cost Fallacy

Tara E. Karns, B.S.

Thesis submitted to the Eberly College of Arts and Sciences at West Virginia University in partial fulfillment of the requirements for the degree of

\author{
Master of Science \\ in \\ Psychology
}

JoNell Strough, Ph.D., Chair

Barry Edelstein, Ph.D.

Elizabeth Kyonka, Ph.D.

Department of Psychology

\author{
Morgantown, West Virginia \\ 2012
}

Keywords: sunk-cost fallacy, age differences, expertise Copyright 2012 Tara E. Karns 


\section{ABSTRACT \\ Age, Expertise, and the Sunk-Cost Fallacy}

\section{Tara E. Karns}

The present study is an investigation of age and expertise differences in the sunk-cost fallacy (SCF), the phenomenon of basing one's decision on past investments rather than the future consequences and/or benefits. The current study used a procedure which required participants to answer sunk-cost vignettes and to justify their answers to the vignettes. Results revealed that demonstration of the SCF decreased with age: young adults demonstrated the fallacy the most frequently and older adults demonstrated it the least frequently. An age by expertise interaction was identified for normatively correct decisions: expert young adults made more normatively correct decisions than naïve young adults. Justifications differed by age group and decision situation: young adults tended to provide justifications related to the salience of the investment as their decision justification when making decisions regarding a dinner situation and middle-aged adults provided justifications of contingencies more frequently in a situation regarding a movie purchase. Young adults' focus on the salience of the previous investment suggested an avoidance of additional loss. 


\section{ACKNOWLEDGEMENTS}

I would like to thank many individuals who contributed suggests, comments, and support during the process of this project. I would like to thank Dr. JoNell Strough, my academic advisor and thesis chair, for her guidance and support during this project, as well as her devotion to my continued professional development. I am also appreciative of the comments and suggestions provided by my committee members, Drs. Barry Edelstein and Elizabeth Kyonka. Additionally, I am especially grateful for the support from my parents. Without their continued guidance and support, I would not be where I am today. 


\section{TABLE OF CONTENTS}

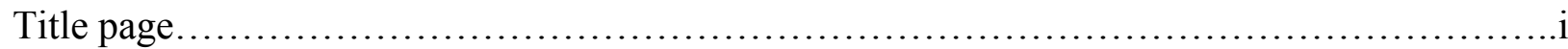





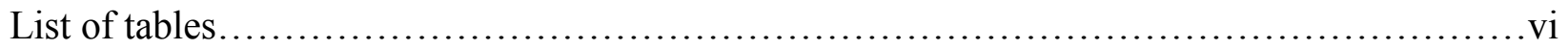

List of figures....................................................................

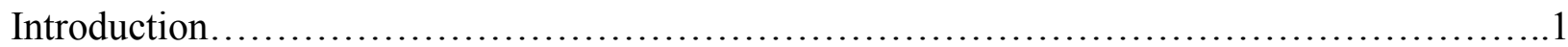

Explanations for the Sunk-Cost Fallacy.............................................................2

Heuristics...................................................................

Loss Aversion..........................................................

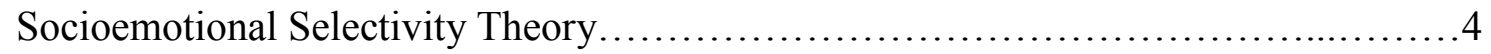

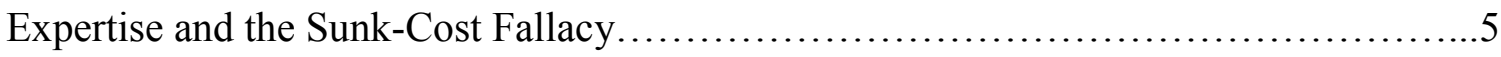

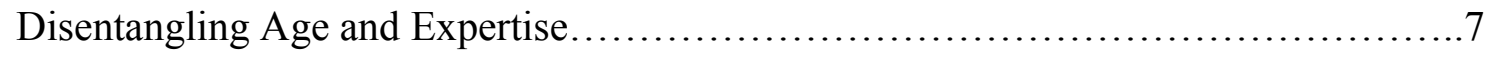

Justifications of Decision-Making Situations................................... 8

Methodological Concerns...................................................10

Effects of Justifying Answers............................................ 10

Past Issues in Measurement of the Sunk-Cost Fallacy.............................11

Numeracy............................................................ 12

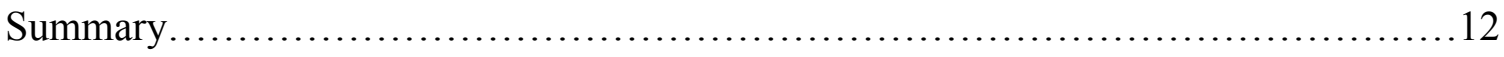

Statement of the Problem.......................................................... 13

Research Questions and Hypotheses..............................................14

Method..........................................................................

Design.................................................................. 15 
Participants............................................................. 15

Procedure...................................................................

Measures................................................................ 19

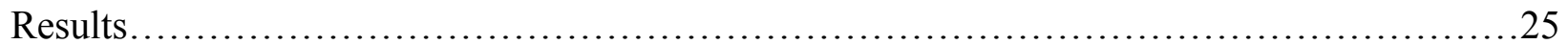

Preliminary Analyses....................................................25

Decisions about Sunk-Cost Situations by Age and Expertise.......................27

Treatment of Sunk-Cost Decisions...............................................

Open-ended Justifications............................................... 30

Multivariate Analysis of Variance on Justifications............................... 31



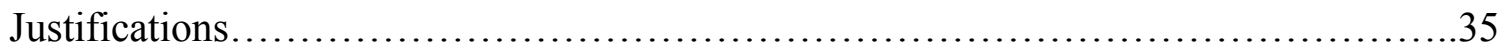

Gist-based Processing................................................... 36



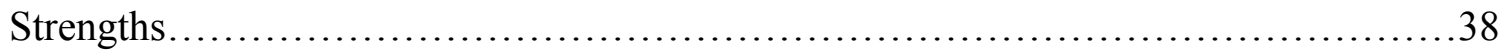

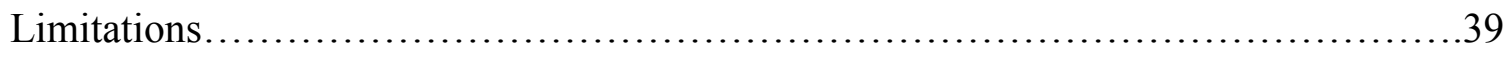

Future Directions........................................................40

Conclusion..........................................................41

References.................................................................42

Tables....................................................................... 47

Figures.....................................................................56

Appendices.....................................................................61 


\section{LIST OF TABLES}

1. Descriptive statistics of sample............................................. 47

2. Overall means, standard deviations, rangers, and reliability for all measures............48

3. Coding categories, definitions, examples, and kappas...........................49

4. Correlations between sunk-cost scores, Resistance to Sunk Costs, DOI, Risky-Choice Framing, Attribute Framing, the SNS, income, and difficulty paying bills...............50

5. Means and standard deviations for ANOVAs on scores for sunk-cost decisions..........51

6. Correlations between sunk-cost score for five vignettes pairs and justification

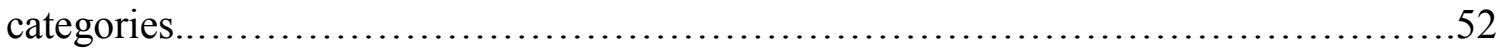

7. ANOVA statistics for coding categories...................................... 53

8. Significant MANOA statistics for decision treatment, age, and expertise..............54

9. Percentage of participants who demonstrated the sunk-cost fallacy for each justification






\section{LIST OF FIGURES}

1. Percentage of young, middle-aged, and older adults who indicated same of differently for

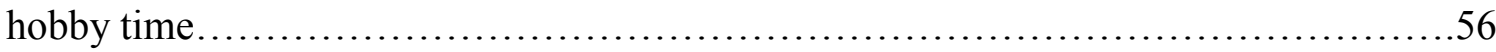

2. Percentage of young, middle-aged, and older adults who indicated same of differently for hobby money.......................................................... 57

3. Percentage of young, middle-aged, and older adults who indicated same of differently for

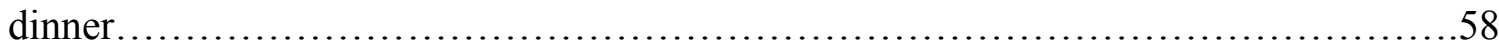

4. Percentage of young, middle-aged, and older adults who indicated same of differently for movie .59

5. Percentage of young, middle-aged, and older adults who indicated same of differently for

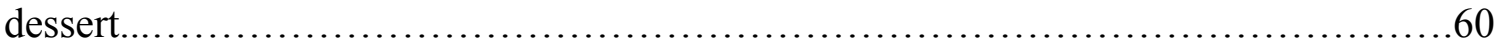




\section{Introduction}

Previous research on decision making has revealed a phenomenon common among humans and widespread in many facets of life: the sunk cost fallacy (SCF) (Arkes \& Ayton, 1999; Arkes \& Blumer, 1985; Bruine de Bruin, Parker, \& Fischhoff, 2007). The SCF is the decision-making error of basing decisions on previous investments of time, money, effort, etc. rather than future consequences or benefits of the decision (Arkes \& Ayton). For example, viewers may decide to spend more time watching a movie despite their disinterest in it because they have spent money to see it. Consequently, in decisions where people are faced with the choice to continue an investment despite negative outcomes or discontinue the investment, many will choose to stay the course of the investment. Although research on the fallacy has varied, much research has focused on decisions regarding monetary investments (Bruine de Bruin et al., 2007; Fennema \& Perkins, 2008; Frisch, 1993). Additionally, although it is clear from previous research that adolescents and young adults demonstrate the fallacy (Klaczynski, 2001; Strough, Mehta, McFall, \& Schuller, 2008), adult age differences in rates of demonstrating the fallacy have not been studied extensively. Strough et al. (2008) and Strough, Schlosnagle, and DiDonato (2011) discovered that older adults demonstrate the fallacy less frequently than younger adults and also make more normatively correct decisions. However, middle-aged adults were not examined. Bruine de Bruin et al. examined age differences among adults (ages 18-88 years) and found that participants' self-reported resistance to sunk costs increased with age, suggesting a decrease in demonstration of the SCF with age. The effect of expertise on the SCF has also been examined (e.g., Fennema \& Perkins), which revealed that accountants and businesspeople are less likely than naïve participants to demonstrate the fallacy. However, in this study and others (e.g., Tan \& Yates, 1995; Larrick, Morgan, \& Nisbett, 1990), age and expertise were confounded. Furthermore, few studies have examined the reasons why participants demonstrate 
the SCF, although one study which did suggested a desire to avoid appearing wasteful (Frisch). The purpose of the present study was to examine age differences and the effect of expertise on the SCF as well as to identify potential reasons for demonstrating the fallacy by asking participants to justify their answers.

\section{Explanations for the Sunk-Cost Fallacy}

\section{Heuristics}

Previous research has posited various reasons for the occurrence of the fallacy, but explanations have yet to be offered. Klaczynski (2001) examined the SCF among children, adolescents, and young adults and reasoned that by adolescence cognitive abilities necessary to make efficient decisions, such as heuristics, have been acquired, but that they are often used inappropriately. Heuristics are mental shortcuts that allow decision makers to make quick, efficient decisions, but do not yield a decision that is always normatively correct (Tversky \& Kahneman, 1982). Adolescents may not be able to separate their heuristic representations from the situation they are currently experiencing (Klaczynski). Decisions can be deemed "normatively correct" or "rational" if they follow the application of rules given the goals of the decision maker in addition to the information that the decision maker has available to them (Reyna, 2006). In this way, rationality is dependent on how consistent the decision maker is according to a set of rules which results in achievement of their goals. In the context of the SCF, a normative (rational) decision is one in which a decision maker makes the same decision in a situation in which an investment has been made as in an analogous situation where no or a very low investment has been made (Klaczynski, 2001). That is, the decision maker should be applying the rule of basing their decision on the future consequences or benefits of a decision. 
Developmentally, previous research has demonstrated that normatively correct decisions are less frequent during childhood, tend to increase during mid-adolescence and then remain stable into young adulthood (Klaczynski, 2001; Klaczynski \& Cottrell, 2004). In addition, research has also demonstrated that older adults tend to make more normatively correct decisions than young adults (Strough et al., 2008; Strough, Schlosnagle, \& DiDonato, 2011). A gap in the literature exists in middle-aged adults, however, so the trajectory of the trend cannot explicitly be stated. However, the current study used middle-aged adults as a comparison group and has been able to address this gap in the research.

More specifically, the "waste not" heuristic, the desire to avoid appearing wasteful, has been cited as a motivation for demonstrating the SCF (Arkes \& Blumer, 1985; Frisch, 1993). Most children are taught not to waste. When they are presented with sunk-cost situations as adolescents, they may attempt to avoid appearing wasteful by basing their decisions on previous investments rather than focusing on the future consequences and benefits. Consequently, they use a learned heuristic in inappropriate situations. However, research has indicated that the rates of demonstrating the SCF decrease in older adulthood (Strough et al., 2008), which Klaczynki's (2001) finding fails to explain because older adults should also be using these learned heuristics. It may be that older adults have gained experience which allows them to determine when to use heuristics appropriately (Strough, Karns, \& Schlosnagle, 2011).

\section{Loss Aversion}

Another possible explanation for the SCF is loss aversion (Soman, 2004). Loss aversion refers to the phenomenon established by Kahneman and Tversky (1979) which states that in decision making, potential losses are more influential than potential gains. For instance, individuals are often hesitant to place a bet, even if it is a perfectly fair one, because the possible 
gain is not large enough to overshadow the possible loss (Kahneman \& Tversky, 1984).

Regarding the age difference in demonstration of the SCF, it may be that young adults are focusing more attention on the losses (the previous investment) than on the possible gains (decision outcome), leading them to demonstrate the fallacy. In addition, young adults are more likely than older adults to be risk seeking in loss rather than gain frames, suggesting that young adults may be more likely to demonstrate the SCF because they are focusing on the previous investment which has already been lost and are seeking to avoid future losses (Mikels \& Reed, 2009).

\section{Socioemotional Selectivity Theory}

As evident by the work of Mikels and Reed (2009), it seems that young adults have a tendency to focus on the previously lost investment and seek a way to avoid future additional loss. Older adults, however, may focus less on the negative information, the previously lost investment, and more on gaining the optimal positive emotional experience (Carstensen \& Mikels, 2005), making them less likely to focus on the money, time, effort, etc. that they may lose in the process. As demonstrated by Mather and Carstensen (2005), socioemotional selectivity theory (SST) may explain this shift in focus of type of information. SST predicts agerelated changes in time perspective, resulting in a more limited time perspective for older adults and greater motivation to focus on positive and emotional information (Carstensen, 1993, 2006; Carstensen, Isaacowitz, \& Charles, 1999). Individuals with a more expansive time perspective, typically young adults, have a tendency to focus on knowledge-related information. For instance, staying to watch a movie they paid for may not enhance an older adult's experience so they are not motivated to do so. Instead of focusing on the money they lost, they may attend to more positive information such as the free time they now have to do something else. However, young 
adults who are focusing on avoiding loss would pay more attention to the money they would lose if they were to leave a movie before it was over. Older adults may not want to waste their time, money, or effort on a situation that they know will not benefit them in the end or enhance their current emotional state, even if they have already invested in the situation.

Previous research has supported the theories of loss aversion and SST as explanation for the SCF. For example, in a study requiring participants to explain their goals when making decisions that involve sunk costs, Strough, Schlosnagle, and DiDonato (2011) found that older adults tended to pay less attention to investment-related information than young adults. However, when the investment was salient, participants tended to make fewer normatively correct decisions and demonstrate the fallacy more frequently, typical of individuals who are seeking to avoid additional loss (Soman, 2004). Moreover, research has also indicated that young adults tend to weigh negative information more heavily in contrast to positive information (Baumeister, Bratslavsky, Finkenauer, \& Vohs, 2001; Smith, Cacioppo, Larsen, \& Chartrand, 2003). In the context of the SCF, older adults may want to avoid focusing on the negative information (the loss of their previous investment) to make their decisions but young adults focus more on the investment that has already been lost. Furthermore, in their review of previous research, Peters, Dieckmann, and Weller (2011) identified older adults as being more susceptible to affective influences than younger adults during decision making, furthering the support for SST.

\section{Expertise and the Sunk-Cost Fallacy}

Although the SCF is investigated most frequently in young adult samples (e.g., Coleman, 2010; Frisch, 1993; Thames, 1996), previous research has also examined the effect of expertise and training on the frequency of demonstration of the SCF (e.g., Fennema \& Perkins, 2008; Garland, Sandefur, \& Rogers, 1990). Typically, these studies provide expert participants with 
situations in which a financial investment has been made (Fennema \& Perkins) and ask them to decide whether they will continue to invest in the situation or not. Fennema and Perkins' research identified individuals with accounting and business expertise to be less likely to demonstrate the SCF than participants without expertise when making a decision about financial situations.

Expertise has also been examined in situations other than financial scenarios. Garland et al. (1990) used petroleum drilling decision-making vignettes and recruited petroleum geologists to participate in their study. The petroleum geologists were less likely than naïve participants to continue with the petroleum expedition investment the higher the sunk costs. The geologists also gave lower estimates on whether the next drilling would be prosperous. The expertise that the petroleum geologists possessed likely helped them determine whether drilling an additional well would be profitable, preventing them from demonstrating the SCF. However, the expertise that the petroleum geologists possessed was not assessed outside of their area of expertise. Prior research has demonstrated that the effect of expertise may be limited to domain-specific situations rather than generalizing to other situations (e.g., Bornstein, Emler, \& Chapman, 1999; Tan \& Yates, 1995). Tan and Yates demonstrated that accounting students were just as likely as non-accounting students to demonstrate the SCF when making a decision about vacationing at a resort, but less likely to demonstrate the SCF when making a business related decision.

The preceding research on expertise and the SCF suggests that participants who have relevant expertise and training regarding financial principles (i.e., MBA students and CPAs) are less likely to demonstrate the fallacy (Fennema \& Perkins, 2008; Garland et al., 1990). Larrick, Morgan, and Nisbett (1990) identified economics professors in their first study and undergraduate students who received a brief training in certain economic and financial concepts 
in their second study to make more normative decisions and consider margins during their decision-making processes compared to those who have no training. These expert and trained participants were also less likely to demonstrate the SCF than untrained participants (Larrick et al., 1990). Moreover, Fennema and Perkins used MBA students, CPAs, and undergraduate accounting majors (juniors and seniors) as their expert groups and undergraduate psychology majors (freshman and sophomores) as their naïve participants. As expected, the MBA students (average of 2 years of work experience) and CPAs (average of 14 years of work experience) demonstrated the SCF less frequently than the undergraduate accounting majors with less expertise and the naïve undergraduate psychology majors.

\section{Disentangling Age and Expertise}

Previous research has investigated the effect of expertise (Fennema \& Perkins, 2008; Garland et al., 1990; Larrick et al., 1990) and age (Bruine de Bruin et al., 2007; Strough et al., 2008; Strough, Schlosnagle, \& DiDonato, 2011) on sunk-cost situations separately. However, there has not been an attempt to disentangle the effect of age and expertise. That is, are older adults less likely to demonstrate the fallacy because they have acquired more experience and can be considered experts? Or does the experience need to be domain-specific such as the knowledge that accountants and businesspeople are privy to given their education and expertise?

Based on previous research (e.g., Strough et al., 2008; Strough, Schlosnagle, \& DiDonato, 2011), older adults may have gained the necessary experience to be considered "experts" in the context of the SCF. That is, during the course of their lifespan, older adults may have sufficiently maintained or experienced gains in "pragmatics" of everyday life (e.g., knowledge which has been acquired due to life experiences). "Life pragmatics" have been defined as wisdom (Baltes, Lindenberger, \& Staudinger, 2006). This wisdom may make older 
adults less susceptible to demonstration of the SCF than younger adults who have not gained the necessary pragmatics to develop higher wisdom. Previous research has demonstrated that young adults with relevant expertise (i.e., accounting majors, trained participants, etc.) are less likely than non-experts to demonstrate the SCF in domain-specific situations (Fennema \& Perkins, 2008), but that they are just as likely to demonstrate the fallacy in domain-general situations (Tan \& Yates, 1995). Overall, older adults who are not experts demonstrate the fallacy less frequently than young adults, suggesting that older adult non-experts have acquired the necessary experience or "wisdom" throughout their lives to make them resistant to demonstration of the fallacy. However, past research has not separated participants into explicit age and expertise groups, failing to disentangle age and expertise in the context of the SCF. To address this issue, expert (i.e., accountants, CPAs, MBAs, etc.) and naïve participants within three age groups (i.e., young, middle, older) were used in the current study.

\section{Justifications of Decision-Making Situations}

Although it is clear from previous research that the SCF is a prominent decision-making phenomenon and age and expertise differences are evident, the cause of these differences is unclear. In addition, there has not been an attempt to disentangle the effects of age and expertise. Frisch (1993) conducted a study in which participants made decisions regarding investment and no or low investment vignettes and were asked to give a justification for their answers. Frisch noted three types of justifications that participants tended to provide: (1) the situations (sunk cost and no sunk cost) are subjectively different from the participant's perspective; (2) the situations are objectively different from the participant's perspective; and (3) the situations are the same in the participant's perspective, in which case the participant did not demonstrate the SCF. For the justification to be considered objectively different, the participant had to state reasons for their 
decision that were based on assumptions they made about the situation rather than on information that was provided. Participants who gave subjectively different responses indicated that they made their decision because they did not want to appear to be "wasteful" or expressed some sort of regret. If participants made different decisions on the vignettes (i.e. demonstrated the SCF) and then later indicated that they were not different, they were categorized as viewing the vignettes as the same. The goal of Frisch's study was to examine whether participants would treat the sunk-cost situations the same or differently and why they would choose to do so, thereby gaining information on the decision-making process individuals use when making decisions about sunk-cost situations. However, Frisch's study was the first of its kind and no other effects (e.g., expertise or age) were examined.

Prior studies on the effect of expertise on the SCF have also examined escalation of commitment to sunk costs (e.g., Heath, 1995) and the decision-making strategies of mental budgeting, and marginal decision making (e.g., Fennema \& Perkins, 2008; Thames, 1996) to examine decision-making processes. Escalation to commitment refers to the phenomenon of continuing commitment to an investment as a response to a previously made investment despite negative consequences (Brockner, 1992; Heath). Heath posits that people may engage in this process as a means of justifying their prior decision to invest in the situation. Mental budgeting is a strategy in which people set a budget for an investment. They then mentally track the investment while continually comparing it to their budget (Heath). If the investment exceeds the budget they have set, they are likely to decrease the amount of their future investments. The process of mental budgeting goes against the fundamental concepts that are taught in economic and accounting courses, such as marginal decision making (Heath). Marginal decision making is a process where the future benefits and costs are weighed carefully in order to make an informed 
decision (Heath), which usually leads to more rational decision making. In studies examining the effect of expertise, mental budgeting is typically used by naïve participants while participants with expertise tended to use a strategy known as marginal decision making (Fennema \& Perkins).

In the present study, to better understand age differences and the effect of expertise in decision-making processes, participants in specific age and expertise groups were required to justify their answers by responding to an open-ended question about the sunk-cost vignettes. A coding scheme was developed to capture the qualitative data and to inspect whether expert and naïve young, middle-aged, or older adults differed in their decision-making processes when making decisions about sunk-cost situations.

\section{Methodological Concerns}

\section{Effects of Justifying Answers}

The act of justifying an answer is the physical and/or mental processes one goes through while explaining a judgment one has made (Johnson \& Kaplan, 1991). Fennema and Perkins (2008) noted that the act of justifying their answers seemed to cause participants to make more normatively correct decisions compared to participants who are not asked to justify their answers. In essence, the participants became more critical of their answers than if they did not give justifications and were more likely to answer rationally. In the context of the SCF, this is an important concept because it may be that when participants are asked to justify their answers they are using a more analytical and critical process to make their decisions (Klaczynski \& Daniel, 2005). Because the justifications in this study are used as a means of examining why individuals demonstrate the SCF, the participants were asked to justify their answers after they 
completed the sunk-cost vignettes and other judgment and decision-making questions to prevent the participants from making more normatively correct decisions than they normally would.

\section{Past Issues in Measurement of the SCF}

The SCF has been examined in most cases through the use of hypothetical vignette situations which participants are supposed to imagine themselves in. However, the vignette situations, the number of vignettes, and the description of sunk-costs have not been consistent from study to study. For instance, Frisch (1993) used three vignette pairs and both Klaczynski (2001) and Strough et al. (2008) used two vignette pairs, although they were variations on two of Frisch's vignettes. Furthermore, Bruine de Bruin et al. (2007) used a measure consisting of 9single items (not pairs) which measured a participant's resistance to demonstration of the SCF. Bruine de Bruin et al.'s vignettes had two options embedded within a single decision situation and participants had to rate on a continuous scale how likely they would be to choose one option over the other option. Participants demonstrated the SCF if they chose the option in which a previous investment had been made rather than the option that did not include the previous investment, which indicated that they were resistant to sunk costs (Strough, Karns, \& Schlosnagle, 2011). In addition, previous research has used a variety of situations ranging from money spent on a hobby (Strough et al., 2008), movie (Frisch), and concert ticket (Tversky \& Kahneman, 1981).

Although the phenomenon of the SCF has been robust across the various measures that have been used, the discrepancies in the measures pose some methodological questions such as generalizability of the results to situations outside of those posed in the vignettes. To address this, a measure consisting of 13 vignette situations about a variety of everyday events with multiple choice options was used in the present study. 


\section{Numeracy}

Individuals low in numeracy have been identified as being more susceptible to extraneous factors in decision situations leading to a higher vulnerability to biases in judgment and decision making (Peters et al., 2006; Reyna, Nelson, Han, \& Dieckmann, 2009). Previous literature has identified individuals who are highly numerate as being more able to accurately use correct numerical principles and less susceptible to framing effects (Peters et al.). In addition, individuals who are low in numeracy have been identified as more vulnerable to irrelevant information in decision-making situations, resulting in susceptibility to framing effects and less than desirable decisions (Peters et al.). Due to the nature of the methods that were used to examine the SCF in this study, numeracy was a factor which could have influenced how likely an individual is to demonstrate the fallacy. The current study required participants to use, read, and interpret amounts of money and time in sunk-cost situations, thus it was important to evaluate whether numeracy was related to rates in demonstration of the fallacy. Other questionnaires in this study also contained questions which are based on probabilities, percentages, monetary amounts, and other numerical properties. To account for the effect of numeracy on judgment and decision making, the Subjective Numeracy Scale (SSN; Fagerlin et al., 2007) was included in this study.

\section{Summary}

Despite recent research on age differences in the SCF, middle-aged adults have not been examined as a distinct age group to investigate the trajectory of the fallacy from young to older adulthood. The current study explored whether age differences in the SCF for naïve participants is linear from young adulthood to old age, with young adults demonstrating the fallacy most frequently. In addition, the current study also examined whether demonstration of the SCF for 
expert participants declines from young adulthood to old age in a similar trend, disentangling the effect of age and expertise. The concern of a more generalizable measure of the SCF was also addressed in this study. Examining justifications for decisions about sunk-cost situations provided insight into potential differences in the decision-making processes for naïve and expert young, middle-aged, and older adults.

\section{Statement of the Problem}

Vulnerability to the SCF tends to decline as individuals reach older adulthood (Strough et al., 2008; Strough, Schlosnagle, DiDonato, 2011). Previous research has also identified expert participants as less likely to demonstrate the SCF than naïve participants (Fennema \& Perkins, 2008). Furthermore, even though it is clear that older adults are less likely and younger adults are more likely to demonstrate the SCF (Strough et al., 2008; Strough, Schlosnagle, \& DiDonato), it is unclear where middle-aged adults fall on the spectrum. The current study included middleaged adults as an age group to address this gap in the literature.

In the current study, by recruiting participants of particular age and expertise groups, it was possible to disentangle the effect of age and expertise. Furthermore, participants were asked to justify their answers, providing a better understanding of the process that occurs when individuals make decisions about sunk-cost situations. Frisch (1993) had participants justify their answers to sunk-cost situations and found that many individuals express the desire to not appear wasteful; however, it is unclear what differences exist between the types of justifications naïve and expert young, middle-aged, and older adults give to support their decisions, specifically when they demonstrate the SCF. Based on prior research (Bruine de Bruin, et al., 2007; Fennema \& Perkins, 2008; Frisch) it was probable that expert middle-aged and older adult participants were more likely than naïve young adult and middle-aged participants to indicate that the 
vignettes are the same. If there is a difference, the results provide more insight into the age and expertise difference among the SCF.

\section{Research Questions and Hypotheses}

\section{Research Question 1}

Are there adult age differences in the SCF?

Hypothesis 1. Based on results obtained from Strough et al. (2008) and Strough, Schlosnagle, and DiDonato (2011), the SCF will decline with age such that young adults will demonstrate the fallacy most frequently, older adults will demonstrate the fallacy least frequently, and middle-aged adults will fall in the middle.

\section{Research Question 2}

Will expertise affect the likelihood of demonstration of the SCF?

Hypothesis 2. Expert participants (i.e. MBA students, current and retired MBAs, and CPAs) will be less likely to demonstrate the SCF than naïve participants, based on Fennema and Perkins (2008).

Hypothesis 3. An age by expertise interaction is expected such that expert middle-aged and older adults as well as naïve older adults will be less likely to demonstrate the SCF than expert young adults and naïve young and middle-aged adults.

\section{Research Question 3}

What type of justifications do naïve young, middle-aged, older adults and expert young, middle-aged, and older adults provide to explain their decisions when faced with a choice where costs have been sunk?

Hypothesis 4 (Revised). Based on Strough, Schlosnagle, and DiDonato (2011), naïve young adults will refer to the salience of the investment more than naïve older adults and expert 
participants. For example, providing justifications that indicate the amount of the investment influences their decision.

Hypothesis 5. Naïve older adults and expert young, middle-aged, and older adults will be more likely than naïve participants to indicate that there is no difference between the investment vignette and its analogous no or low investment vignette, based on the results Fennema and Perkins (2008) reported.

\section{Method}

\section{Design}

The current study used a 2 (expertise: naïve and expert) x 3 (age: young, middle-aged, and older adults) between-subjects design.

\section{Participants}

Data from 130 participants were collected: 56 young adults (25 naïve, 31 expert), 37 middle-aged adults (24 naïve, 13 expert), and 37 older adults ( 27 naïve, 10 expert). The descriptive statistics of the sample can be found in Table 1. Expert young adults had a significantly higher GPA than naïve young adults, $t(50)=-2.65, p=.01$ (Table 1 ). Subjective numeracy was also measured and can be found in Table 1.

To disentangle the effects of age and expertise, expert participants were recruited within three age groups. Half of the young, middle-aged, and older adults were experts or had related training (i.e., MBAs, MBA students, and CPAs) and the other half were naïve participants with no expertise or related training. By including three groups of participants with and without relevant expertise, the interaction between the two and the main effect of each were able to be examined. 
For young adults, experts $(M=4.55, S D=.91)$ indicated that they were more familiar with the SCF than naïve subjects $(M=1.24, S D=.83), t(52)=-13.88, p<.001$. The Levene's test was significant for middle-aged adults indicating that the variances were unequal so the unequal variances assumed statistics were examined, indicating a significant difference between expert and naïve middle-aged adults, $t(15.35)=-4.14, p=.001$. Expert middle-aged adults $(M=$ $3.38, S D=1.71)$ reported that they were more familiar with the SCF than naïve middle-aged adults $(M=1.29, S D=.86)$. The Levene's test was also significant for older adults indicating unequal variances. Examination of the unequal variances assumed statistics revealed no significant differences between expert and naïve older adults, $t(8.37)=-1.62, p=.14$. However, the equal variances assumed analysis revealed that there was a significant difference with expert older adults $(M=2.00, S D=1.41)$ indicating more familiarity than naïve older adults $(M=1.15$, $S D=.78)$

Independent samples t-tests were also conducted to examine if there was a significant age difference in years between expert and naïve participants. Expert young adults $(M=19.48, S D=$ 2.82) were significantly older than naïve young adults $(M=21.63, S D=2.59), t(53)=-2.95, p=$ .005. Naïve middle-aged adults $(M=53.42, S D=4.26)$ were significantly older than expert middle-aged adults $(M=48.38, S D=6.59), t(35)=2.82, p=.008$. Naïve older adults $(M=$ 75.62, $S D=7.76)$ were significantly older than expert older adults $(M=69.50, S D=6.93), t(34)$ $=2.18, p=.04$.

Naïve young adult participants were recruited from undergraduate psychology classes at West Virginia University. Twenty-four participants chose to receive course credit and one participant chose to receive $\$ 10.00$ as compensation. Naïve middle-aged and older adults were recruited from the surrounding community by personal referrals, community bulletin board 
advertisements, and Craigslist and Facebook advertisements. Older adults were also recruited from two senior centers in Pittsburgh, PA. All naïve middle-aged and older adults were given $\$ 10.00$ as compensation.

The expert groups were participants who had specific training: accounting (CPAs) or business (MBAs). These criteria were used by Fennema and Perkins (2008) to create an expert group. Young adult experts were recruited from Accounting 201 and 202: Principles of Accounting at West Virginia University. By the time they participated in this study they had already been educated on the SCF and also taken an examination which included the SCF as an examination topic. Twenty-six expert young adults chose to receive course credit and four chose to receive $\$ 10.00$ as compensation. More expert young adults were seniors while the majority of the naïve young adults were freshman (Table 1). The expert young adults also had higher GPAs than the naïve young adults.

Middle-aged and older adult experts were recruited through personal referrals and local businesses. The participants either had a relevant education or degree (e.g., associate's or bachelor's degree in accounting, business, CPA, MBA) or had over 10 years of business or accounting experience. All middle-aged and older adult experts received $\$ 10.00$ as compensation.

\section{Procedure}

Each participant was given a cover letter explaining the benefits and risks of the study before participating. All portions of the study were completed in a written format. One hundred nineteen participants completed the study in the presence of a researcher and 11 participants received the materials by mail with detailed instructions on completing the study. Participants read instructions for completing the sunk-cost questions (see Appendix A), which was comprised 
of the analogous investment and no or low investment sunk-cost vignettes. Additional judgment and decision-making questions were used as distracters (see Appendix B). The sunk-cost vignettes and distractor judgment and decision-making questions were broken into four sections given one at a time in one of four randomized orders. The analogous pairs were made up of one vignette which had a high investment and one vignette which contained no investment or a very small investment. As the participants read the sunk-cost vignettes they were told to imagine themselves in the situation which they were reading. After reading each vignette, the participants had to decide how long they would continue with the hypothetical situation or if they would remove themselves from the situation by choosing one of the five multiple choice options provided (example provided in measures). To prevent participants from looking at both the investment and no or low investment vignettes at the same time, the participants completed half of the sunk-cost vignettes, followed by half of the distractor judgment and decision-making vignettes, and then finished the second half of the sunk-cost vignettes and the rest of the distractor judgment and decision-making vignettes. The vignettes for the present study were adapted from Frisch (1993), Tversky and Kahneman (1981), and Strough et al. (2008). New vignettes also were created for this study based on pilot testing (see Appendix A). Items 1-3, 5-7, and 13 were created for this study. Items 9, 10, and 12 were adapted from Frisch. Item 4 was adapted from Tversky and Kahneman. Items 8 and 11 were adapted from Strough et al. (2008).

After completing all of the sunk-cost vignettes and judgment and decision-making distractors, the participants completed the justification section (see Appendix C). They were presented with five of the vignette pairs again, this time one vignette and its analogous counterpart at the same time. They were asked to indicate whether they thought the two situations should be treated the same or differently (modeled after Frisch's (1993) procedure) 
and if so, their justification for treating the situations portrayed in the vignettes the same or differently. After completing the justification section, the participants completed the DOI (Bruine de Bruin et al., 2007; see Appendix D). Participants then completed the Resistance to Sunk Costs measure (Bruine de Bruin et al., 2007; see Appendix E) followed by the Subjective Numeracy Scale (Fagerlin et al., 2007; see Appendix F) and a demographics questionnaire (see Appendix G). At the conclusion of the study, participants were debriefed on the purpose of the study, paid $\$ 10.00$ if they preferred to receive the money, and provided with further information if they had questions.

\section{Measures}

Demographics. The demographic questionnaire completed by each participant assessed gender, race, ethnicity, age, sex, marital status, highest education attained, current or previous major, type of job of longest employment, current job, income, and questions regarding difficulty paying bills (Appendix G).

Sunk-Cost Fallacy and Normatively Correct Decisions. The sunk-cost measure was developed by analyzing pilot data that was collected before the start of the study. Undergraduate psychology students $(N=644)$ completed the questionnaire which was made up of 16 vignettes at the time $(\alpha=.59)$. Upon examination of the reliability by item deletion, three items in particular appeared to lower the reliability (see Appendix H). When these three items were removed from the scale, the reliability was at an acceptable level $(\alpha=.70)$. Thirteen sunk-cost items were left to form the sunk-cost measure (Appendix A).

First, participants received one half of the sunk-cost vignettes made up of one of the analogous investment and no or low investment pairs. The following is an example of an investment vignette: 
"You are staying in a hotel room on vacation. You paid \$10.95 to see a movie on pay TV. After 5 minutes, you are bored and the movie seems pretty bad. How much longer would you continue to watch the movie?"

An analogous, no investment vignette is the following:

"You are staying in a hotel room on vacation. You turn on the TV and there is a movie on. After 5 minutes, you are bored and the movie seems pretty bad. How much longer would you continue to watch the movie?"

Participants then read the following statement:

"Think about this situation as you normally would. Which of the following courses of action would you select?"

They were given the five following choice alternatives to choose from:

(a) stop watching entirely; (b) watch for 10 more minutes; (c) watch for 20 more minutes; (d) watch for 30 more minutes; or (e) watch until the end.

These investment and no or low investment pairs were used to assess demonstration of the SCF. Second, participants completed 14 judgment and decision-making questions (Bruine de Bruin et al., 2007). Seven of the questions measured risky-choice framing and seven of the questions measured positive and negative attribute framing. Third, participants completed the second half of the sunk-cost vignettes. Finally, participants completed the second half of the judgment and decision-making questions.

Scoring. Each sunk-cost decision was scored in three different ways. The first score, dichotomous scoring, indicated whether the participant demonstrated the fallacy for a given vignette pair. If the participants indicated that they would continue with the situation in the investment vignette longer than in the analogous no or low investment vignette, they 
demonstrated the SCF (Klaczynski, 2001). A score of 0 indicated that they did not demonstrate the fallacy and a score of 1 indicated that they did demonstrate the fallacy. Scores were summed across the vignettes with a higher score indicating that they demonstrated the SCF more frequently (see Table 2 for descriptive statistics).

The second method of scoring sunk-cost decisions assessed the degree of overinvestment among those who demonstrated the fallacy. Each multiple choice response alternative from the investment and no investment vignettes was assigned a numerical value (e.g., $1=$ stop with the situation and $5=$ continue with the situation until it is complete). For each pair of vignettes, total points were acquired by subtracting the response alternative point values (investment vignette minus analogous no or low investment vignette) and then summing across the vignettes. For example, if a participant chose response alternative $\mathrm{E}$ for the investment vignette, they received 5 points. If they chose response alternative A for the analogous vignette, they received 1 point. Subtraction between those two response alternative indicates a degree of overinvestment of 4 for that vignette pair. Each participant received an average degree of overinvestment score created by averaging the degree of overinvestment across the 13 vignettes (see Table 2).

Third, the number of normatively correct responses across all vignettes was calculated. A normatively correct response refers to the instances where participants answered the vignettes (investment and no investment) the same (Klaczynski, 2001). A score of 0 indicates that the participant did not give a normatively correct response and a score of 1 indicates that the answer was normatively correct (see Table 2).

Knowledge. To examine the participants' knowledge of the SCF, a question (see Appendix $\mathrm{G}$ - last item) was given to participants at the end of the study to examine whether or not they had heard of the SCF (see Table 1 for means). 
Justifications. Following Frisch's (1993) procedure for obtaining justifications, participants were presented with five of the investment and no or low investment vignettes again after they indicated their decision for all vignettes (Appendix C). They were asked, "Should these vignettes be treated the same or differently? If they should be treated differently, why? If they should be treated the same, why?" The instructions indicated to the participant that they needed to include enough information in their justification to support their answer in the case that it would be questioned by someone.

Coding Scheme for Justifications. The participants' answers to the justification questions were coded to determine what kind of justification was used most frequently when the participants demonstrate the SCF or make normatively correct decisions. During initial coding 20 coding categories were used. However, it quickly became evident that three of the categories (monetary difference, time difference, and effort difference) were close in definition to the coding category of "investment salience", making it very difficult to differentiate between these categories. In addition, very few participants gave responses which could be coded as "monetary difference," "time difference," or "effort difference", resulting in very low kappas. To eliminate this high association between the categories and make the coding scheme more succinct, the three "difference" categories were collapsed into "investment salience". In addition, two coding categories "differences apparent" and "I don't know" were initially part of the original coding scheme. However, these two categories were not used so they were eliminated from the scheme, leaving a total of 15 coding categories (see Table 3 for definitions, examples, and kappas). The coding scheme was developed for this study by examining responses from pilot data and adjusting a previously used coding scheme by Strough, Schlosnagle, and DiDonato (2011). 
The justification responses were broken down into idea units by two coders (intraclass $r=$ .98). Following Strough and Diriwächter (2000), idea units were defined as the answer to a "what" question and contained a verb that formed the central idea of the unit and also any explanations about "why", "when”, “where”, "who", or "how”. Two coders independently coded the naïve young adult $(n=22)$ and naïve older adult $(n=26)$ participant responses. Both coders were blind to age and expertise group. Inter-rater reliability (average $\kappa=.82$ ) was based on 20 participant responses (10 naïve young adults, 10 naïve older adults). After reliability was established, the coding was completed by one coder and 25 participant responses ( 5 per vignette situation) were checked to ensure reliability (average $\kappa=.78$ ). The same procedure was followed for the expert young and older adults and all middle-aged adults $(n=82)$, though a different coder was used. Reliability was once again established (average $\kappa=.88$ ) and a reliability check indicated that the reliability decreased some but was still acceptable (average $\kappa=.80$ ). Any disagreements in coding were resolved through consensus of the coders. The overall average kappa was .85 for the coding categories for all participants between both coding partners. See Table 3 for weighted averages between the kappas for each coding categories.

A proportion score was calculated for each coding category. First, proportions were calculated for each coding category within its respective vignette situation. The proportions were calculated by dividing the number of times a participant gave a particular coding situation by their number of idea units. For example, a proportion was calculated for the coding category of investment salience in the dessert vignette. If a participant mentioned investment salience twice and had a total of 5 idea units, their proportion score for investment salience was .40. Second, proportion averages were calculated by summing the proportions for each coding category across 
the 5 vignettes, divided by five. The average proportion scores for each justification coding category were used in the analyses which can be found in the results section.

Decision Outcomes Inventory. After participants completed the justification questionnaire, they completed the DOI (Bruine de Bruin et al., 2007; Appendix D). The DOI includes behaviors (e.g. done your own laundry; had any kind of job) and possible negative outcomes of those behaviors (e.g. ruined your clothes because you didn't follow the laundry instructions on the label; quit a job after a week) to examine whether participants' decisions typically have positive or negative outcomes. Participants were asked if they have had the opportunity to make such decisions and also if they have experienced the negative outcome as a result of making the decision. The DOI allows the opportunity to examine whether the participants tend to avoid negative outcomes when making decisions or if they typically make poor decisions. Such a checklist permits a clearer understanding of the types of decisions and outcomes that each participant experiences and whether the SCF relates to "real world" decisions.

Resistance to Sunk Costs. Each participant completed the Resistance to Sunk Costs measure which consists of ten vignettes in a written format (Bruine de Bruin et al., 2007; Appendix E). The vignettes permitted an investigation of each participant's resistance to demonstrating the SCF. The following is an example of a vignette: "You decide to learn to play a musical instrument. After you buy an expensive cello, you find you are no longer interested. Your neighbor is moving and you are excited that she is leaving you her old guitar, for free. You'd like to learn how to play it." Participants are then asked, "Would you be more likely to practice the cello or the guitar?" They rated their response on a six point scale ranging from 1 (most likely to play cello) to 6 (most likely to play guitar). Resistance to sunk costs is measured 
by the average rating for each participant across the 10 items. A higher average score indicates that the participant is more resistant to demonstrating the SCF than participants who have a lower average score.

Subjective Numeracy Scale. The Subjective Numeracy Scale (SNS; Fagerlin et al., 2007; Appendix F) is an 8-item scale: four items measure a person's belief about their own abilities to perform mathematical operations and four items measure a person's preference about how numerical information is presented. A higher score means that a participant has a high selfreported numeracy whereas a lower score means that a participant has a low self-reported numeracy. Because the current study uses judgment and decision-making questions which contain various amounts of time, money, percentages, etc. measuring numeracy is important in the case that participants are not comfortable dealing with such numbers.

\section{Results}

\section{Preliminary Analyses}

Grand means and standard deviations for each measure can be found in Table 2.

Correlations. Correlations were conducted to examine the association between the sunkcost and judgment and decision-making questions (risky-choice and attribute framing), the Resistance to Sunk Costs measure, the Decision Outcomes Inventory (Bruine de Bruine et al, 2007), the Subjective Numeracy Scale (Fagerlin et al., 2007), and participants'self-reported income and difficulty in paying bills (see Table 4). The three methods of scoring sunk-cost decisions were significantly correlated and also significantly related to Resistance to Sunk Costs (Bruine de Bruin et al., 2007). Self-reported numeracy and participants' resistance to sunk costs was also significantly correlated. Income and difficulty in paying bills was significant correlated with normatively correct decisions, Resistance to Sunk Costs, and the Decisions Outcomes 
Inventory (Bruine de Bruin et al.). Correlations between the three methods of scoring sunk-cost decisions and income were conducted to examine if there was a significant association between them. There was a significant correlation between income and normatively correct scores; however, upon further examination it become evident that the significant association was due to a shift in the amount of income that young adults reported as compared to middle-aged and older adults. When a partial correlation was conducted controlling for age, the association between income and normatively correct decisions was no longer significant. However, when controlling for income, the association between age and normatively correct decisions was still significant. The same trend was found when further examining participants' difficulty in paying bills. Similar correlations were found for each age group and naïve and expert participants.

Normality. To address Hypotheses 1, 2, and 3, separate two-way analyses of variance (ANOVA) were conducted on the three methods of scoring sunk-cost decisions (dichotomous, degree of overinvestment, and normatively correct). First, normality was assessed by examining the skewness, kurtosis, and the Kolmogorov-Smirnov statistics. All three methods of scoring the sunk-cost decisions had significant Kolmogorov-Smirnov statistics indicating that the data were not normal. A closer look revealed that the dichotomous scoring was positively skewed and had a negative kurtosis. The degree of overinvestment scoring was also positively skewed and had a negative kurtosis. The normatively correct scoring was negatively skewed and also had a negative kurtosis. To address this issue, a square root and log transformation was implemented. However, this did not fix the normality, and tended to reverse whether the scores had a negative or positive skewness and kurtosis. Because the normality could not be addressed using transformations, nonparametric analyses were used. A two-way nonparametric test is not available so separate Kruskal-Wallis analyses were used for age and expertise. In addition, three 
individual Mann-Whitney U analyses were used to assess the age differences. The results were the same as the parametric analyses. Because of this and that readers tend to be more accustomed to reading parametric statistics, the parametric analyses are reported here. The two-way analysis of variance (ANOVA) also allows age and expertise to be examined at once and an interaction effect to be analyzed, which the nonparametric analyses do not.

\section{Decisions about Sunk-Cost Situations by Age and Expertise}

Dichotomous scoring. To address the first and second research question, a two-way between-groups ANOVA was conducted to examine the impact of age and expertise on the SCF, as assessed by the dichotomous scoring. The Levene's test was not significant indicating that the variances did not differ. The participants were divided into three age groups: young adults (ages 18-33 years), middle-aged adults (ages 35-59 years), and older adults (ages 60-88 years). In addition, participants were either naïve or experts. There was a statistically significant main effect for age, $F(2,123)=11.51, p<.001, \eta_{p}{ }^{2}=.16$, as was hypothesized. Post-hoc comparisons using the Tukey HSD analysis indicated that, as expected, young adults demonstrated the SCF more frequently than middle-aged and older adults. There was not a significant difference between middle-aged and older adults (means and standard deviations can be found in Table 5). In contrast to hypotheses 2 and 3, the main effect for expertise was not statistically significant, $F(1,123)=3.77, p=.05$. The interaction between age and expertise was also not significant, $F(2,123)=.37, p=.69$.

Degree of overinvestment. Second, a two-way between-groups ANOVA was used to investigate the impact of age and expertise on the average degree of overinvestment. The Levene's test was not significant. A significant main effect was obtained for age, $F(2,121)=$ $6.98, p=.001, \eta_{p}{ }^{2}=.10$. Post-hoc comparisons using the Tukey HSD analysis indicated that 
young adults tended to overinvest more than older adults; however, there was no significant difference between young and middle-aged adults, or between the older and middle-aged adults (means and standard deviations can be found in Table 5). The main effect for expertise was not statistically significant, $F(1,121)=1.57, p=.21$. There was also not a significant interaction between age and expertise, $F(2,121)=.26, p=.78$.

Normatively correct decisions. A two-way between-groups ANOVA was used to assess the effect of age and expertise on normatively correct decisions. The Levene's test was not significant. There was a main effect for age, $F(2,59)=11.48, p<.001, \eta_{p}{ }^{2}=.28$. Post-hoc comparisons using the Tukey HSD analysis indicated that young adults made significantly fewer normatively correct decisions than middle-aged and older adults. The difference between middleaged and older adults was not significant (means and standard deviations can be found in Table $5)$. The main effect for expertise was not significant, $F(1,59)=1.26, p=.26$. However, the interaction between age and expertise was significant, $F(2,59)=3.71, p=.03, \eta_{p}{ }^{2}=.11$.

To investigate this interaction further, a simple effects analysis was conducted to examine age differences within the expert and naïve groups. A significant difference was identified between naïve and expert young adults, $F(1,26)=9.66, p=.01, \eta_{p}{ }^{2}=.27$. Expert young adults $(M=8.88, S D=2.53)$ made significantly more normatively correct decisions than naïve young adults $(M=6.17, S D=1.90)$. There was not a significant difference among naïve and expert middle-aged and older adults.

Sunk-cost score from decision treatment. A 2 (expertise: naïve vs. expert) x 3 (age group: young, middle-aged, and older adults) ANOVA was conducted using age and expertise as the independent variables and a sunk-cost score created from the justification questionnaire. The sunk-cost score was derived from the answer participants gave when asked if they would treat 
the five sunk-cost situations (dessert, dinner, hobby time, hobby money, and movie) the same or differently. Participants received a 0 if they indicated they would treat the situations the same and a 1 if they indicated they would treat the situations differently. The scores for each vignette pair were then summed across to create a sunk-cost score. Because participants were instructed to provide justifications for these situations as well, this score is an accurate representation of what participants decided after seeing the situations side-by-side. Correlations between this new sunk-cost score and the justification categories can be found in Table 6.

Similar to the results reported for the overall sunk-cost score, a significant main effect of age was identified, $F(2,119)=3.45, p=.004, \mathrm{np} 2=.09$. Young adults $(M=2.68, S D=1.64)$ demonstrated the SCF more frequently than older adults $(M=1.72, S D=1.65)$. There was not a significant difference between middle-aged adults and young and older adults. The main effect of expertise was not significant and there was not a significant age by expertise interaction.

\section{Treatment of Sunk-Cost Decisions}

Five 3 (age group) x 2 (expertise group) x 2 (decision treatment) chi-square analyses, one for each vignette pair in the justification section, were conducted to examine if age and expertise were associated with participants' answers about whether they would treat the sunk-cost situations with and without an investment the same or differently. The expected count was above 5 for each cell in each of the five chi-square analyses. Neither age nor expertise was significant for the hobby time (Figure 1), hobby money (Figure 2), or dinner (Figure 3) vignette pairs.

Age was significant for the movie pair, $\chi^{2}(2, N=128)=15.94, p<.001$ (Figure 4). Of the participants who indicated that they would treat the vignettes the same, $25.9 \%$ were young adults, $32.8 \%$ were middle-aged adults, and $41.1 \%$ were older adults. Of the participants who indicated that they would treat the vignette pair differently, $58.6 \%$ were young adults, $25.7 \%$ 
were middle-aged adults, and $15.7 \%$ were older adults. Expertise was not significant, $\chi^{2}(1, N=$ $128)=.04, p=.85$. However, of the naïve participants, $44.6 \%$ indicated they would treat the situations the same and 55.4\% indicated they would treat them differently. Of the expert participants, $46.3 \%$ indicated they would treat the situations the same and $53.7 \%$ indicated they would treat them differently.

For the dessert pair, age was also significant, $\chi^{2}(2, N=130)=11.36, p=.003$ (Figure 5). The trend for the dessert pair was similar to the movie pair. Of the participants who indicated that the vignette pair should be treated the same, $33.7 \%$ were young adults, $32.6 \%$ were middleaged adults, and $33.7 \%$ were older adults. Of the participants who indicated that the vignettes should be treated differently, $65.8 \%$ were young adults, $18.4 \%$ were middle-aged adults, and $15.8 \%$ were older adults. Expertise was not significant for the dessert pair, $\chi^{2}(1, N=130)=.23$, $p=.63$. However, of the naïve participants, $72.4 \%$ indicated they would treat the situations the same and $27.6 \%$ indicated they would treat the situations differently. Of the expert participants, $68.5 \%$ indicated they would treat the situation the same and $31.5 \%$ indicated they would treat the situations differently.

\section{Open-Ended Justifications}

To address Hypothesis 4 and 5, 153 (age group) x 2 (expertise) ANOVA were conducted using the average proportion of each coding category across the 5 vignette pairs as the dependent variables. In this way, age and expertise were examined by each coding category. The significant results can be found in Table 7.

Statistically significant main effects for age were identified for three categories: investment salience, emotional salience, and the amount of investment does not matter. Young adults $(M=.37, S D=.24)$ tended to mention the salience of the investment more frequently than 
middle-aged $(M=.21, S D=.21)$ and older adults $(M=.21, S D=.27)$. No difference was found between middle-aged and older adults. Older adults $(M=.16, S D=.18)$ tended to mention the emotional salience of an investment more than middle-aged adults $(M=.08, S D=.12)$. No difference was found between young adults $(M=.10, S D=.13)$ and middle-aged and older adults. Moreover, middle-aged adults $(M=.09, S D=.09)$ tended to state that the amount of the investment did not matter more frequently than young $(M=.02, S D=.05)$ and older adults $(M=$ $.03, S D=.09$ ); no difference was identified between young and older adults.

\section{Multivariate Analysis of Variance on Justifications}

Five separate 3 (age group) x 2 (expertise group) x 2 (decision treatment) multivariate analyses of variance (MANOVA) were conducted for the justification coding category proportions, one for each vignette pair (i.e., dessert, dinner, hobby time, hobby money, and movie). The significant results can be found in Table 8 .

Dessert vignette pair. Significant effects for age, expertise, and interactions were not identified. A significant decision treatment effect was identified for investment salience and personal characteristics (see Table 8). Participants provided investment salience as a justification more frequently when they indicated the vignette pair should be treated differently $(M=.69, S D$ $=.36)$ rather than the same $(M=.05, S D=.14)$. Participants gave justifications based on personal characteristics more frequently when they indicated that the vignettes should be treated the same $(M=.22, S D=.36)$ rather than differently $(M=.03, S D=.11)$.

Dinner vignette pair. No significant expertise effects were identified. A significant decision treatment effect was identified for investment salience and health outcomes (Table 8). Participants provided investment salience as a justification more often when they indicated that the vignettes should be treated differently $(M=.50, S D=.42)$ rather than the same $(M=.08, S D$ 
$=.22$ ). Health outcomes were provided as justifications more often when participants indicated that the vignettes should be treated the same $(M=.41, S D=.39)$ rather than differently $(M=.10$, $S D=.25)$ Significant age effects were also identified for investment salience and personal characteristics. Post hoc analyses revealed that young adults $(M=.29, S D=.39)$ provided investment salience as a justification more frequently than middle-aged adults $(M=.10, S D=$ $.19)$. No significant difference was identified between older adults $(M=.20, S D=.41)$ and young and middle-aged adults. Young adults $(M=.06, S D=.18)$ also provided personal characteristics as a justification more often than middle-aged adults $(M=.13, S D=.26)$. No difference was identified between older adults $(M=.05, S D=.15)$ and young and middle-aged adults. A significant decision by age interaction was identified for personal characteristics. Further analysis revealed that, of the participants who indicated that the vignettes should be treated differently, there was a significant difference between young and middle-aged adults and middle-aged and older adults, $F(2,37)=6.90, p=.003, \eta_{p}{ }^{2}=.27$. That is, when participants indicated that the vignettes should be treated differently, middle-aged adults $(M=.29, S D=.32)$ provided personal characteristics more frequently than young $(M=.05, S D=.14)$ and older adults $(M=.00, S D=.00)$. No difference was found among the age groups for those who indicated the vignettes should be treated the same, $F(2,85)=.02, p=.98$.

Hobby time vignette pair. There were no main effects of age or expertise and no interactions. Main effects of decision treatment were identified for investment salience, emotional salience, closure, no difference, and amount of investment does not matter (see Table 8). Investment salience was provided as a justification more frequently when participants indicated the vignettes should be treated differently $(M=.64, S D=.39)$ rather than the same $(M$ $=.03, S D=.11)$. Emotional salience was provided as a justification more frequently when 
participants indicated the vignettes should be treated the same $(M=.33, S D=.42)$ rather than differently $(M=.04, S D=.16)$. Closure was provided as a justification more frequently when participants indicated that the vignettes should be treated differently $(M=.03, S D=.12)$ rather than the same $(M=.01, S D=.04)$. Participants indicated that there was no difference between the vignettes more frequently when they indicated that the vignettes should be treated the same $(M=.07, S D=.21)$ rather than differently $(M=.00, S D=.00)$. Participants also indicated that the amount of the investment does not matter more frequently when they indicated that the vignettes should be treated the same $(M=.09, S D=.22)$ rather than differently $(M=.00, S D=$ $.00)$.

Hobby money vignette pair. There were no main effects of age or expertise and no interactions. There was a significant decision treatment effect for investment salience, emotional salience, and no difference (see Table 8). Investment salience was provided as a justification by participants more frequently when they indicated that the vignettes should be treated differently $(M=.60, S D=.40)$ rather than the same $(M=.04, S D=.16)$. Emotional salience was provided by participants more frequently when they indicated that the vignettes should be treated the same $(M=.26, S D=.41)$ rather than differently $(M=.07, S D=.21)$. Participants indicated that there was no difference between the vignettes when they indicated that the vignettes should be treated the same $(M=.07, S D=.23)$ rather than differently $(M=.00, S D=.00)$.

Movie vignette pair. No significant effect of expertise was identified. Significant decision treatment effects were identified for investment salience and emotional salience (see Table 8). Investment salience was provided as a justification by participants more frequently when they indicated that the vignettes should be treated differently $(M=.54, S D=.46)$ rather than the same $(M=.04, S D=.16)$. Emotional salience was provided as a justification more 
frequently by participants when they indicated that the vignettes should be treated the same $(M=$ $.25, S D=.38)$ rather than differently $(M=.12, S D=.25)$. A significant effect of age was identified for contingencies. Post hoc analyses revealed that middle-aged adults $(M=.09, S D=$ .22) provided a justification of contingencies more frequently than young $(M=.01, S D=.04)$ and older adults $(M=.00, S D=.00)$. No difference was identified between young and older adults. A significant three-way interaction (age $\mathrm{x}$ expertise $\mathrm{x}$ decision treatment) was identified for emotional salience. Upon examination it was evident that naïve young adults were giving emotional salience as their justification more frequently when they indicated that the vignettes should be treated the same $(M=.40, S D=.55)$ rather than differently $(M=.02, S D=.07)$. However, no other significant effects were found for expert participants, age, and decision treatment on emotional salience.

Summary of MANOVA results. No main effects of age and expertise were identified for the dessert, hobby time, and hobby money vignette pairs. However, significant effects of age (but not of expertise) were identified for the dinner and movie vignette pairs. All five vignette pairs had significant effects of decision treatment. Furthermore, a few important trends emerged across the vignettes. A decision treatment effect was identified for investment salience across all five vignette pairs. The participants provided investment salience as a justification more frequently when they indicated that the vignettes should be treated differently. In addition, significant decision treatment effects were identified for emotional salience in the hobby money, hobby time, and movie vignette pairs, with participants providing emotional salience as a justification more frequently when they indicated the vignettes should be treated the same. Similarly, participants indicated that there was no difference between the vignettes when they indicated that the vignettes in the in the hobby time and money pairs should be treated the same. 


\section{Discussion}

As expected, young adults demonstrated the SCF more frequently than middle-aged and older adults and their average degree of overinvestment was greater. In addition, young adults were also less likely to make normatively correct decisions than middle-aged and older adults. An interaction between age and expertise was identified for normatively correct decisions. Naïve young adults tended to make fewer normatively correct decisions than expert young adults. These findings correspond to previous research which has identified naïve young adults as more likely to demonstrate the SCF and less likely to make normatively correct decisions than expert participants (Tan \& Yates, 1995). However, the results did not fully replicate those of Fennema and Perkins (2008) whereas expert participants overall were less likely to demonstrate the SCF than naïve participants.

\section{Justifications}

Overall, the prior investment was more salient to young adults than middle-aged and older adults in their justification for their decisions. Young adults may be focusing more on the potential losses rather than the potential gains of a sunk-cost situation. As a result, they are more likely to demonstrate the SCF. The results correspond to the theories of loss aversion as an explanation for demonstration of the SCF (Soman, 2004). This finding is also similar to the findings of Strough, Schlosnagle, and DiDonato (2011) in their study on decision-making goals in which the investment was less salient to older adults than young adults when they described their decision-making goals.

When justifying their decisions, older adults tended to provide emotional information more frequently than middle-aged adults. This finding is consistent with socioemotional selectivity theory (Carstensen, Isaacowitz, \& Charles, 1999). If the emotional elements of a 
situation are important to older adults when making decisions, they may demonstrate the SCF less frequently because they are focusing on optimizing their current emotional state, as evident by a negative correlation between sunk-cost scores and emotional salience (see Table 6).

Middle-aged adults were more likely than young and older adults to state that the amount of the investment did not matter when they were asked to justify their decisions. Though previous research has not utilized middle-aged adults as a comparison age group, it is likely that middle-aged adults have moved past the investment being most salient to their decision-making process, but have not reached the age where they are seeking to optimize their emotional experiences. Essentially, they are in the "middle" of the life-span trend of sunk-cost decisions.

Despite the differences in justification responses, middle-aged and older adults tended to demonstrate the SCF at similar rates. Although they justify their decisions differently, both age groups are not focused on the investment which has already been "sunk", which could be making them less vulnerable to the SCF. Further examination of the justifications for each vignette pair revealed that middle-aged adults were more likely than young and older adults to state personal characteristics as a justification for their decisions when they indicated that they would treat the dinner vignette pair differently and young adults were more likely than middle-aged adults to provide investment salience as a justification. These age differences in the types of justifications given by participants for a particular type of vignette could be an indication of the difference decision-making processes they used to make their decisions, such as whether loss aversion or gist-based reasoning was influencing the decision.

\section{Gist-Based Processing}

The relations between age, the salience of the investment, and emotional information also are consistent with Reyna's (2004) theory of the development of gist-based processing. Older 
adults may be more likely than young and middle-aged adults to rely on what Reyna describes as the "gist" of the situation. That is, the gist representation is the global meaning of the decisionmaking situation that the individual has interpreted rather than the specific details. Because gists do not contain verbatim details regarding situations, cognitive load is also reduced when gists are used. By focusing on the gist, older adults may be focusing less on the specific details of the investment and more on their gist interpretation, which may include information about their current emotional state. Developmentally, decision-making biases which are based on gists should increase with age due to experience, making older adults more vulnerable to gist-based decision-making biases. However, in this study, older adults were less vulnerable to demonstration of the SCF, indicating that their focus on the gist of the situation might have made them less susceptible to the fallacy. As evident by the types of justifications the participants provided, older adults tended to focus on more emotional information indicating that their gist was emotion-based. By having an emotion-based focus, older adults may have been able to avoid demonstrating the SCF unlike young adults who had a tendency to provide investment salient justifications.

\section{Expertise}

The results of the current study did not fully replicate those of Fennema and Perkins (2008) with regards to the effect of expertise. However, expert young adults were identified as making more normatively correct decisions than naïve young adults, similar to the findings of Tan and Yates (1995). Furthermore, the means and standard deviations for the scores of sunkcost decisions for expert and naïve participants, though not significantly different, were in the expected direction. Though the results of Fennema and Perkins were not fully replicated, differences in the methods used in the current study could be responsible for the discrepancy. For 
instance, the sunk-cost situations that Fennema and Perkins used in their study were financial business situations which the expert participants were accustomed to dealing with. Because this study used everyday situations, it is possible that the education the expert participants had in accounting and business did not transfer, reducing the effect of expertise on demonstration of the SCF. For instance, Tan and Yates (1995) demonstrated that although accounting students were less likely than non-accounting students to demonstrate the fallacy in financial situations, they were just as likely as the non-accounting students to demonstrate the fallacy in a situation involving a decision about a ski resort vacation.

In addition, Fennema and Perkins did not have explicit age groups in their study when examining the effect of expertise. For example, they used undergraduate psychology and accounting majors, MBA students who had an average of 2 years of work experience, and CPAs who had an average of 14 years of work experience. They did not provide the age of their participants, thus it is possible that age and expertise were confounded in their study.

\section{Strengths}

Previous research has used a limited number of vignettes to measure the SCF. Frisch (1993) used three vignette pairs and both Klaczynski (2001) and Strough et al. (2008) used two vignette pairs that were variations on two of Frisch's vignettes. Furthermore, Bruine de Bruin et al. (2007) measured participants' resistance to sunk costs using 9 vignettes. In the current study, 13 vignette pairs were used to measure the SCF. By using a greater number of vignettes one aim was to develop sunk-cost situations that a greater number of people could relate to. Despite the differences in the measures that have been used to investigate the SCF, age differences have been identified across a variety of measures, suggesting it is a robust phenomenon. 
In addition, although one study has examined goals related to sunk-cost situations (Strough, Schlosnagle, \& DiDonato, in press), only one other previous study has examined justifications for sunk-cost situations (Frisch, 1993). Frisch only used three coding categories, which may not have captured the entire essence of a participant's justification. In the current study, the procedure Frisch used to ask participants to justify their answers was replicated, but 15 coding categories were used. This procedure allowed the opportunity to more fully examine the justifications that the participants gave, revealing differences in the types of justifications that young, middle-aged, and older adults used to support their decisions in sunk-cost situations. For example, young adults tended to focus on the salience of the previous investment, middle-aged adults indicated that the amount of the investment did not matter, and older adults focused on the emotionally salient elements. The differences in types of justifications young, middle-aged, and older adults gave for their decision about sunk-cost situations helped in interpreting the types of decision-making processes used by decision makers.

\section{Limitations}

The current study used hypothetical vignettes that required participants to imagine themselves in the situation. Although the vignettes were adapted and created carefully, such methods are not as precise as observing actual behaviors. It is often difficult for individuals to imagine themselves in situations with which they are unfamiliar. In addition, the Resistance to Sunk Costs measure and Attribute Framing (Bruine de Bruin et al., 2007) were used to examine participants' resistance to demonstrating the SCF and their vulnerability to positive and negative attribute framing. The Resistance to Sunk Costs measure was significantly associated with the sunk-cost vignettes adapted and developed for this study. However, the reliability for these scales was less than ideal, making it difficult to confidently draw any conclusions. 
In addition, an examination of the percentage of SCF demonstration across the 13 vignettes indicated that some vignettes had a lower rate than others (see Table 9). For example, the vignette pair about the fitness club (Appendix A; item \#2) had a low percentage (12.3\%) of SCF demonstration while the movie vignette had a relatively high percentage (53.8\%). The variation in percentage across the vignettes may indicate that some situations may be more common and easier to relate to than others. Development of vignettes or another measure which more individuals can relate to could improve the literature on the SCF. Furthermore, the difference in demonstrate of the SCF across vignettes could be the results of a magnitude effect. That is, the amount of money that participants are willing to spend on a fitness club membership differs greatly from the amount of money they are willing to spend for a movie. What is deemed expensive for one situation may not be for another situation.

\section{Future directions}

In the future, developing vignettes that can apply to all individuals should be a major goal. Although the vignettes in this study were adapted and created with caution and precision, it is difficult for each individual to be able to relate to each situation. A computer simulation task in which the situation changes depending on an individual's answer to pretest questions could more accurately assess their likelihood of demonstrating the SCF. However, such a method would be difficult to perfect given the idiosyncratic tendencies and experiences that individuals have.

In a replication of this study, it would be prudent to include a financial, accounting or business-like task to examine if expert participants would be more or less likely to demonstrate the SCF as compared to everyday situations such as ones that were used in this study. Because the expert participants in this study may not have transferred their knowledge regarding the SCF 
to the everyday situations, including a business-like decision situation would allow for comparison.

\section{Conclusion}

The results of this study suggest that the demonstration of the SCF decreases from young to older adulthood, with middle-aged adults demonstrating the SCF at similar rates as older adults. Young adults tended to demonstrate the SCF most frequently and the prior investment is more salient to them when they justify their decisions. This may indicate an aversion to loss. Moreover, middle-aged adults are most likely to mention that the amount of the investment does not matter when making a decision whereas older adults focus more on the emotional salience of the situation. Although this study failed to fully replicate the findings of Fennema and Perkins (2008) regarding the effect of expertise, improvements in the method could help attenuate this discrepancy. 


\section{References}

Arkes, H. R. \& Ayton, P. (1999). The sunk cost and Concorde effects: Are humans less rational than lower animals? Psychological Bulletin, 125(5), 591-600.

Arkes, H. R. \& Blumer, C. (1985). The psychology of sunk cost. Organizational Behavior and Human Decision Processes, 35, 125-140.

Baltes, P. B., Lindenberger, U. \& Staudinger, U. M. (2006). Life span theory in developmental psychology. In R. M. Lerner, W. Damon (Eds.) Handbook of child psychology (6 ${ }^{\text {th }}$ Ed.): Vol. 1, Theoretical models of human development. 1029-1143.

Baumeister, R. F., Bratslavksy, E., Finkenauer, C., \& Vohs, K. D. (2001). Bad is stronger than good. Review of General Psychology, 5(4), 323-370. doi: 10.1037//1089-2680.5.4.323

Bornstein, B. H., Emler, A. C., \& Chapman, G. B. (1999). Rationality in medical treatment decisions: Is there a sunk-cost effect? Social Science \& Medicine, 49, 215-222.

Brockner, J. (1992). The escalation of commitment to a failing course of action: Toward theoretical progress. Academy of Management Review, 17(1), 39-61.

Bruine de Bruin, W., Parker, A. M., \& Fischhoff, B. (2007). Individual differences in adult decision-making competence. Journal of Personality and Social Psychology, 92(5), 938956. doi: $10.1037 / 0022-3514.92 .5 .938$

Carstensen, L. L. (1993). Motivation for social contact across the life span: A theory of socioemotional selectivity. In J. E. Jacobs (Ed.) Nebraska Symposium on Motivation, 1992: Developmental perspectives on motivation. 209-254. Lincoln, NE: University of Nebraska Press.

Carstensen, L. L. (2006). The influence of a sense of time on human development. Science, 312(5782), 1913-1915. doi: 10.1126/science.1127488 
Carstensen, L.L., Isaacowitz, D. M, \& Charles, S. T. (1999). Taking time seriously: A theory of socioemotional selectivity. American Psychologist, 54(3), 165-181. doi: 10.1037/0003066X.54.3.165

Carstensen, L. L. \& Mikels, J. A. (2005). At the intersection of emotion and cognition: Aging and the positivity effect. Current Directions in Psychological Science, 14(3), 117-121. doi: 10.1111/j.0963-7214.2005.00348.x

Coleman, M. D. (2010). Sunk cost and commitment to medical treatment. Current Psychology, $29,121-134$.

Fagerlin, A., Zikmund-Fisher, B. J., Ubel, P. A., Jankovic, A., Derry, H. A., \& Smith, D. M. (2007). Measuring numeracy without a math test: Development of the Subjective Numeracy Scale. Medical Decision Making, 27, 672-680.

Fennema, M. G. \& Perkins, J. D. (2008). Mental budgeting versus marginal decision making: Training, experience, and justification effects on decisions involving sunk costs. Journal of Behavioral Decision Making, 21, 225-239. doi: 10.1002/bdm.585

Frisch, D. (1993). Reasons for framing effects. Organizational Behavioral and Human Decision Processes, 54, 399-429. doi: 10.1006/obhd.1993.1017

Garland, H., Sandefur, C. A., \& Rogers, A. C. (1990). De-escalation of commitment in oil exploration: When sunk costs and negative feedback coincide. Journal of Applied Psychology, 75(6), 721-727. doi: 10.1037/0021-9010.75.6.721

Heath, C. (1995). Escalation and de-escalation of commitment in response to sunk costs: The role of budgeting in mental accounting. Organizational Behavior and Human Decision Processes, 62(1), 38-54. doi: 10.1006/obhd.1995.1029 
Johnson, V., \& Kaplan, S. (1991). Experimental evidence on the effects of accountability on auditor judgments. Auditing: A Journal of Practice \& Theory, 10, 96-107 (Supplement).

Kahneman, D. \& Tversky, A. (1979). Prospect theory: An analysis of decision under risk, Econometrica, 47, 263-291.

Kahneman, D. \& Tversky, A. (1984). Choices, values, and frames. American Psychologist, 39(4), 341-350.

Kim, S., Healey, M. K., Goldstein, D., Hasher, L., \& Wiprzycka, U. J. (2008). Age differences in choice satisfaction: A positivity effect in decision making. Psychology and Aging, 23(1), 33-38. doi: 10.1037/0882-7974.23.1.33

Klaczynski, P. A. (2001). Analytic and heuristic processing influences on adolescent reasoning and decision-making. Child Development, 72(3), 844-861. doi: 10.1111/1467-8624.00319

Klaczynski, P. A. \& Cottrell, J. M. (2004). A dual-process approach to cognitive development: The case of children's understanding of sunk cost decisions. Thinking \& Reasoning, 10(2), 147-174. doi: 10.1080/13546780442000042

Klaczynski, P. A. \& Daniel, D. B. (2005). Individual differences in conditional reasoning: A dual-process account. Thinking \& Reasoning, 11(4), 305-325. doi:

$10.1080 / 13546780442000196$

Larrick, R. P., Morgan, J. N., \& Nisbett, R. E. (1990). Teaching the use of cost-benefit reasoning in everyday life. Psychological Science, 1(6), 362-37

Mather, M. \& Carstensen, L. L. (2005). Aging and motivated cognition: The positivity effect in attention and memory. Trends in Cognitive Science, 9(10), 196-502. 
Mickels, J. A. \& Reed, A. E. (2009). Monetary losses do not loom large in later life: Age differences in the framing effect. Journal of Gerontology: Psychological Sciences, 64B(4), 457-460.

Peters, E., Dieckmann, N. F., \& Weller, J. (2011). Age differences in complex decision making. In K. W. Schaie, S. L. Willis (Eds.) Handbook of the psychology of aging ( $7^{\text {th }}$ Ed.). 133151.

Peters, E., Vastjfall, D., Slovic, P., Mertz, C. K., Mazzocco, K., \& Dickert, S. (2006). Numeracy and decision making. Psychological Science, 17(5), 407-413.

Reyna, V. F. (2004). How people make decisions that involve risk: A dual-process approach. Current Directions in Psychological Science, 13(2), 60-66.

Reyna, V. F. (2006). Risk and rationality in adolescent decision making: Implications for theory, practice, and public policy. Psychological Science in the Public Interest, 7(1), 1-44.

Reyna, V. F., Nelson, W. L. Han, P. K., \& Dieckmann, N. F. (2009). How numeracy influences risk comprehension and medical decision making. Psychological Bulletin, 135(6), 943973.

Smith, N. K., Cacioppo, J. T., Larsen, J. T., \& Chartrand, T. L. (2003). May I have your attention, please: Electrocortical responses to positive and negative stimuli. Neuropsychologia, 41, 171-183. doi: 10.1016/S0028-3932(02)00147-1

Soman, D. (2004). Framing, loss aversion, and mental accounting. In D.J. Koehler \& N. Harvey (Eds.), Blackwell handbook of judgment and decision making (pp. 379-398). Malden, MA: Blackwell.

Strough, J. \& Diriwachter, R. (2000). Dyad gender differences in preadolescents' creative stories. Sex Roles, 43(1-2), 43-60. 
Strough, J., Mehta, C. M., McFall, J. P., \& Schuller, K. L. (2008). Are older adults less subject to the sunk-cost fallacy than younger adults? Psychological Science, 19(7), 650-652. doi: 10.1111/j.1467-9280.2008.02138.x

Strough, J., Karns, T. E., \& Schlosnagle, L. (2011). Decision making heuristics and biases across the life span. Annals of the New York Academy of Sciences.

Strough, J., Schlosnagle, L., \& DiDonato, L. (2011). Understanding decisions about sunk costs from older and younger adults’ perspectives. Journal of Gerontology: Psychological Sciences, 66B(6), 681-686.

Tabachnick, B. G. \& Fidell, L. S. (2007) Using multivariate statistics $\left(5^{\text {th }}\right.$ ed.). New York: Harper Collins.

Tan, H. \& Yates, J. F. (1995). Sunk cost effects: The influences of instruction and future return estimates. Organizational Behavior and Human Decision Processes, 63(3), 311-319.

Thames, E. A. (1996). The sunk-cost effect: The importance of context. Journal of Social Behavior and Personality, 11(4), 817-826.

Tversky, A. \& Kahneman, D. (1981). The framing of decisions and the psychology of choice. Science, 211(4481), 453-458.

Tversky, A. \& Kahneman, D. (1982). Judgment under certainty: Heuristics and biases. In D. Kahneman, P. Slovic, \& A. Tversky (Eds.) Judgment under certainty: Heuristics and biases. 3-22. 
Table 1

Descriptive statistics of sample

\begin{tabular}{|c|c|c|c|c|c|c|}
\hline & \multicolumn{2}{|c|}{$\begin{array}{l}\text { Young Adults } \\
\quad(N=56)\end{array}$} & \multicolumn{2}{|c|}{$\begin{array}{l}\text { Middle-Aged Adults } \\
\qquad(N=37)\end{array}$} & \multicolumn{2}{|c|}{$\begin{array}{l}\text { Older Adults } \\
\quad(N=37)\end{array}$} \\
\hline & $\begin{array}{c}\text { Naïve } \\
(N=25)\end{array}$ & $\begin{array}{c}\text { Expert } \\
(N=31)\end{array}$ & $\begin{array}{c}\text { Naïve } \\
(N=24)\end{array}$ & $\begin{array}{c}\text { Expert } \\
(N=13)\end{array}$ & $\begin{array}{c}\text { Naïve } \\
(N=27)\end{array}$ & $\begin{array}{c}\text { Expert } \\
(N=10)\end{array}$ \\
\hline Age & $M=19.48$ & $M=21.63$ & $M=53.42$ & $M=48.38$ & $M=75.62$ & $M=69.5$ \\
\hline Gender & $\mathrm{F}(n=13 ; 52 \%)$ & $\mathrm{M}(n=16 ; 51.6 \%)$ & $\mathrm{F}(n=18 ; 75 \%)$ & $\mathrm{F}(n=7 ; 53.8 \%)$ & $\mathrm{F}(n=17 ; 63 \%)$ & $\mathrm{F}(n=7 ; 70 \%)$ \\
\hline Marital status & $\begin{array}{l}\text { Never married } \\
(n=25 ; 100 \%)\end{array}$ & $\begin{array}{l}\text { Never married } \\
(n=28 ; 90.3 \%)\end{array}$ & $\begin{array}{l}\text { Married } \\
(n=21 ; 87.5 \%)\end{array}$ & $\begin{array}{l}\text { Married } \\
(n=8 ; 61.5 \%)\end{array}$ & $\begin{array}{l}\text { Widowed or widower } \\
(n=14 ; 51.9 \%)\end{array}$ & $\begin{array}{l}\text { Married } \\
(n=4 ; 40 \%)\end{array}$ \\
\hline Ethnicity & $\begin{array}{l}\text { Not Hispanic or } \\
\text { Latino } \\
(n=24 ; 96 \%)\end{array}$ & $\begin{array}{l}\text { Not Hispanic or Latino } \\
(n=28 ; 90.3 \%)\end{array}$ & $\begin{array}{l}\text { Not Hispanic or Latino } \\
(n=19 ; 79.2 \%)\end{array}$ & $\begin{array}{l}\text { Not Hispanic or } \\
\text { Latino } \\
(n=13 ; 100 \%)\end{array}$ & $\begin{array}{l}\text { Not Hispanic or Latino } \\
(n=16 ; 59.3 \%)\end{array}$ & $\begin{array}{l}\text { Not Hispanic or Latino } \\
(n=8 ; 80 \%)\end{array}$ \\
\hline Race & $\begin{array}{l}\text { White or Caucasian } \\
(n=21 ; 84 \%)\end{array}$ & $\begin{array}{l}\text { White or Caucasian } \\
(n=28 ; 90.3 \%)\end{array}$ & $\begin{array}{l}\text { White or Caucasian } \\
(n=23 ; 95.8 \%)\end{array}$ & $\begin{array}{l}\text { White or Caucasian } \\
(n=12 ; 92.3 \%)\end{array}$ & $\begin{array}{l}\text { White or Caucasian } \\
(n=26 ; 96.3 \%)\end{array}$ & $\begin{array}{l}10 \text { White or Caucasian } \\
(n=10 ; 100 \%)\end{array}$ \\
\hline Employment & $\begin{array}{l}\text { Unemployed } \\
(n=13 ; 52 \%)\end{array}$ & $\begin{array}{l}\text { Part time } \\
(n=16 ; 51.6 \%)\end{array}$ & $\begin{array}{l}\text { Full time } \\
(n=17 ; 70.8 \%)\end{array}$ & $\begin{array}{l}\text { Full time } \\
(n=12 ; 92.3 \%)\end{array}$ & $\begin{array}{l}\text { Fully retired } \\
(n=21 ; 77.8 \%)\end{array}$ & $\begin{array}{l}\text { Fully retired } \\
(n=6 ; 60 \%)\end{array}$ \\
\hline Education & $\begin{array}{l}\text { H.S. or GED } \\
(n=24 ; 96 \%)\end{array}$ & $\begin{array}{l}\text { H.S. or GED } \\
(n=23 ; 74.2 \%)\end{array}$ & $\begin{array}{l}\text { H.S. or GED } \\
(n=10 ; 41.7 \%)\end{array}$ & $\begin{array}{l}\text { Bachelor's } \\
(n=7 ; 53.8 \%)\end{array}$ & $\begin{array}{l}\text { H.S. or GED } \\
(n=20 ; 74.1 \%)\end{array}$ & $\begin{array}{l}\text { Bachelor's } \\
(n=3 ; 30 \%)\end{array}$ \\
\hline Income & $\begin{array}{l}<\$ 10 \mathrm{k} \\
(n=22 ; 88 \%)\end{array}$ & $\begin{array}{l}<\$ 10 \mathrm{k} \\
(n=20 ; 64.5 \%)\end{array}$ & $\begin{array}{l}\$ 70 \mathrm{k} \text { or more } \\
(n=11 ; 45.8 \%)\end{array}$ & $\begin{array}{l}\$ 70 \mathrm{k} \text { or more } \\
(n=10 ; 76.9 \%)\end{array}$ & $\begin{array}{l}\$ 10 \mathrm{k}-19 \mathrm{k} \\
(n=8 ; 29.6 \%)\end{array}$ & $\begin{array}{l}\$ 70 \mathrm{k} \text { or more } \\
(n=3 ; 30 \%)\end{array}$ \\
\hline Parental income & $\begin{array}{l}\$ 70 \mathrm{k} \text { or more } \\
(n=9 ; 36 \%)\end{array}$ & $\begin{array}{l}\$ 70 \mathrm{k} \text { or more } \\
(n=20 ; 64.5 \%)\end{array}$ & $\mathrm{N} / \mathrm{A}$ & N/A & N/A & N/A \\
\hline Year in school & $\begin{array}{l}\text { Freshman } \\
(n=15 ; 60 \%)\end{array}$ & $\begin{array}{l}\text { Seniors } \\
(n=16 ; 51.6 \%)\end{array}$ & N/A & $\mathrm{N} / \mathrm{A}$ & $\mathrm{N} / \mathrm{A}$ & $\mathrm{N} / \mathrm{A}$ \\
\hline GPA & $M=3.07$ & $M=3.41^{*}$ & $\mathrm{~N} / \mathrm{A}$ & N/A & N/A & N/A \\
\hline Numeracy & $M=30.88$ & $M=35.60 *$ & $M=34.33$ & $M=40.08^{* *}$ & $M=28.16$ & $M=31.00$ \\
\hline SCF Familiarity & $M=1.24$ & $M=4.55^{*}$ & $M=1.29$ & $M=3.38 * *$ & $M=1.15$ & $M=2.00$ \\
\hline
\end{tabular}

Note. ${ }^{*}=$ significantly different from naïve young adults; $* *$ = significantly different from naïve middle-aged adults. 
Table 2

Overall means, standard deviations, ranges, and reliability for all measures

\begin{tabular}{|c|c|c|c|c|}
\hline Measure & $M$ & $S D$ & Range & $\alpha$ \\
\hline $\begin{array}{l}\text { Dichotomous scores } \\
(n=129)\end{array}$ & 3.26 & 2.44 & $0.00-10.00$ & .66 \\
\hline $\begin{array}{l}\text { NC scores } \\
(n=65)\end{array}$ & 9.15 & 2.61 & $4.00-13.00$ & .67 \\
\hline $\begin{array}{l}\text { Degree of } \\
\text { overinvestment scores } \\
(n=127)\end{array}$ & .69 & .55 & $0.00-2.08$ & .62 \\
\hline $\begin{array}{l}\text { Resistance to Sunk } \\
\text { Costs } \\
(n=130)\end{array}$ & 4.42 & .83 & $2.00-6.00$ & .56 \\
\hline $\begin{array}{l}\text { SNS } \\
(n=126)\end{array}$ & 33.08 & 7.78 & $8.00-46.00$ & .77 \\
\hline $\begin{array}{l}\text { Risky-Choice Framing } \\
(n=124)\end{array}$ & -3.34 & 4.92 & $10.00-20.00$ & .76 \\
\hline $\begin{array}{l}\text { Attribute Framing } \\
(n=114)\end{array}$ & 3.46 & 6.90 & $0.00-61.00$ & .39 \\
\hline $\begin{array}{l}\text { DOI } \\
(n=130)\end{array}$ & .14 & .07 & $0.03-0.41$ & .76 \\
\hline
\end{tabular}


Table 3

Coding categories, definitions, examples, and kappas

\begin{tabular}{|c|c|c|c|}
\hline Code & Definition & Example & Kappa \\
\hline $\begin{array}{l}\text { 1. Investment } \\
\text { salience }\end{array}$ & $\begin{array}{l}\text { Amount of money, time, effort, } \\
\text { etc. influences decision }\end{array}$ & $\begin{array}{l}\text { "If I paid } \$ 10.95 \text { for a movie, I } \\
\text { would finish watching it." }\end{array}$ & .97 \\
\hline $\begin{array}{l}\text { 2. Emotional } \\
\text { salience }\end{array}$ & $\begin{array}{l}\text { Emotional elements or reasons } \\
\text { influences decision }\end{array}$ & $\begin{array}{l}\text { “...you're bored and your } \\
\text { feelings won't change..." }\end{array}$ & .91 \\
\hline 3. Health outcomes & $\begin{array}{l}\text { Health-related outcomes } \\
\text { influences decision }\end{array}$ & $\begin{array}{l}\text { "You shouldn't risk the dangers } \\
\text { of eating a meal that was } \$ 1 \ldots \text { "... }\end{array}$ & .93 \\
\hline 4. Avoiding waste & $\begin{array}{l}\text { Avoidance of waste is } \\
\text { influencing the decision }\end{array}$ & "I'm not a wasteful person..." & .93 \\
\hline $\begin{array}{l}\text { 5. Personal } \\
\text { characteristics }\end{array}$ & $\begin{array}{l}\text { Participant refers to their own } \\
\text { personal characteristics as the } \\
\text { reason for their decision }\end{array}$ & "I always finish what I start." & .83 \\
\hline 6. Social norms & $\begin{array}{l}\text { Reference to social norms, } \\
\text { values, morals as reasons for the } \\
\text { decision }\end{array}$ & $\begin{array}{l}\text { "I wouldn't want the restaurant to } \\
\text { think that I was being rude." }\end{array}$ & 1.00 \\
\hline 7. Closure & $\begin{array}{l}\text { An expression of a desire to } \\
\text { move on and put the situation in } \\
\text { the past }\end{array}$ & $\begin{array}{l}\text { "...would be easier to quit and } \\
\text { start over..." }\end{array}$ & .72 \\
\hline 8. No difference & $\begin{array}{l}\text { Participant states that there is no } \\
\text { difference between the vignettes }\end{array}$ & "The situations are the same." & .88 \\
\hline $\begin{array}{l}\text { 9. Amount doesn't } \\
\text { matter }\end{array}$ & $\begin{array}{l}\text { The amount of money, time, } \\
\text { effort, etc. is not relevant }\end{array}$ & $\begin{array}{l}\text { "Regardless of the money spent, I } \\
\text { would stop eating." }\end{array}$ & .93 \\
\hline 10. Contingencies & $\begin{array}{l}\text { Participant gives information that } \\
\text { depends on the outcome of a } \\
\text { decision }\end{array}$ & $\begin{array}{l}\text { "I would watch the movie for } 20 \\
\text { more minutes; if it is still boring, } \\
\text { I would turn it off." }\end{array}$ & .66 \\
\hline $\begin{array}{l}\text { 11. General } \\
\text { comments }\end{array}$ & $\begin{array}{l}\text { Participants repeats information } \\
\text { from the vignettes }\end{array}$ & "The dessert is sweet." & \\
\hline $\begin{array}{l}\text { 12. Reasoned } \\
\text { assumptions }\end{array}$ & $\begin{array}{l}\text { Participant adds an inference or } \\
\text { explanation about "what must } \\
\text { have happened" or make an } \\
\text { inference based on something } \\
\text { they already knew }\end{array}$ & $\begin{array}{l}\text { "...if concern is about money, } \\
\text { losing that small amount will } \\
\text { help you later because healthcare } \\
\text { is often expensive..." }\end{array}$ & .75 \\
\hline 13. Missing response & No response & & 1.00 \\
\hline 14. Advice & $\begin{array}{l}\text { Participant suggests what one } \\
\text { could do in such a situation }\end{array}$ & $\begin{array}{l}\text { "You could always get a doggy } \\
\text { bag to go." }\end{array}$ & .85 \\
\hline 15. Other & Unclassifiable response & "Life is short!" & .80 \\
\hline
\end{tabular}


Table 4

Correlations between sunk-cost scores, Resistance to Sunk Costs, DOI, Risky-Choice Framing, Attribute Framing, the Subjective Numeracy Scale, income, and difficulty paying bills

\begin{tabular}{|c|c|c|c|c|c|c|c|c|c|c|}
\hline Measure & 1. & 2. & 3. & 4. & 5. & 6. & 7. & 8. & 9. & 10. \\
\hline $\begin{array}{l}\text { 1. Dichotomous } \\
\text { Scores }\end{array}$ & & $-.95 * *$ & $.91 * *$ & $-.27 * *$ & -.10 & -.04 & .01 & .06 & -.13 & -.07 \\
\hline 2. NC Scores & & & $-.85 * *$ & $.34 * *$ & .15 & .13 & -.08 & .04 & $.38 * *$ & $.31 *$ \\
\hline $\begin{array}{l}\text { 3. Degree of } \\
\text { Overinvestment }\end{array}$ & & & & $-.27 * *$ & -.13 & -.01 & -.08 & .10 & -.07 & -.08 \\
\hline $\begin{array}{l}\text { 4. Resistance to } \\
\text { Sunk Costs }\end{array}$ & & & & & -.08 & .03 & .14 & $.24 * *$ & $.32 * *$ & $.24 * *$ \\
\hline 5. DOI & & & & & & .01 & .10 & .02 & $.29 * *$ & $.34 * *$ \\
\hline $\begin{array}{l}\text { 6. Risky-Choice } \\
\text { Framing }\end{array}$ & & & & & & & .12 & -.02 & .04 & .08 \\
\hline $\begin{array}{l}\text { 7. Attribute } \\
\text { Framing }\end{array}$ & & & & & & & & .02 & -.07 & .05 \\
\hline 8. SNS & & & & & & & & & $.23 *$ & $.28 * *$ \\
\hline 9. Income & & & & & & & & & & $.37 * *$ \\
\hline $\begin{array}{l}\text { 10. Difficulty } \\
\text { paying bills }\end{array}$ & & & & & & & & & & \\
\hline
\end{tabular}

Note. ${ }^{* *} p<.01,{ }^{* *} p<.05 ; \mathrm{NC}=$ Normatively correct; DOI = Decisions Outcome Inventory; SNS = Subjective Numeracy Scale; the DOI, Resistance to Sunk Costs, Risky-Choice and Attribute Framing are from Bruine de Bruin et al. (2007); the SNS is from Fagerlin et al. (2007) 
Table 5

Means and standard deviations for ANOVAs on scores for sunk-cost decisions

\begin{tabular}{|c|c|c|c|c|c|c|}
\hline \multirow[b]{2}{*}{ Measure } & \multicolumn{2}{|c|}{ Naïve } & \multicolumn{2}{|c|}{ Expert } & \multicolumn{2}{|c|}{ Total } \\
\hline & $M$ & $S D$ & $M$ & $S D$ & $M$ & $S D$ \\
\hline \multicolumn{7}{|c|}{ Dichotomous scores $(n=129)$} \\
\hline Young Adults & 4.99 & 2.61 & 3.68 & 2.51 & 4.26 & 2.62 \\
\hline Middle-Aged Adults* & 3.09 & 2.07 & 2.50 & 2.03 & 2.86 & 2.04 \\
\hline Older Adults* & 2.30 & 2.02 & 1.70 & 1.49 & 2.14 & 1.89 \\
\hline Total & 3.44 & 2.50 & 3.02 & 2.35 & 3.26 & 2.44 \\
\hline \multicolumn{7}{|l|}{ NC scores $(n=65)$} \\
\hline Young Adults & 6.17 & 1.90 & 8.88 & 2.53 & 7.71 & 2.62 \\
\hline Middle-Aged Adults* & 10.89 & 1.76 & 10.00 & 2.97 & 10.53 & 2.26 \\
\hline Older Adults* & 10.00 & 2.06 & 10.20 & 1.30 & 10.05 & 1.89 \\
\hline Total & 9.00 & 2.74 & 9.37 & 2.45 & 9.15 & 2.61 \\
\hline \multicolumn{7}{|c|}{ Degree of Overinvestment $(n=127)$} \\
\hline Young Adults & .97 & .58 & .75 & .56 & .85 & .58 \\
\hline Middle-Aged Adults & .74 & .52 & .63 & .53 & .42 & .52 \\
\hline Older Adults* & .43 & .43 & .38 & .39 & .69 & .41 \\
\hline Total & .71 & .56 & .66 & .54 & .69 & .55 \\
\hline
\end{tabular}

Note. $\mathrm{SC}=$ Sunk cost; $\mathrm{NC}=$ Normatively correct; *indicates age difference: significantly different from young adults (total means and standard deviations) 
Table 6

Correlations between sunk-cost score for five vignette pairs and justification categories

\begin{tabular}{|c|c|c|c|c|c|c|c|c|c|c|c|c|c|}
\hline 1 & 2. & 3. & 4. & 5. & 6. & 7. & 8. & 9. & 10. & 11. & 12. & 13. & 14. \\
\hline 1. SC score & $.77 * *$ & $-.29 * *$ & $-.24 *$ & -.10 & $-.21 *$ & .16 & -.06 & $-.20 *$ & $-.28 * *$ & -.01 & .02 & -.09 & $-.25 * *$ \\
\hline $\begin{array}{l}\text { 2. Investment } \\
\text { salience }\end{array}$ & & $-.39 * *$ & $-.28 * *$ & -.10 & $-.23 * *$ & -.04 & -.07 & -.12 & $-.22 *$ & -.13 & .01 & -.15 & -.15 \\
\hline $\begin{array}{l}\text { 3. Emotional } \\
\text { salience }\end{array}$ & & & $.26 * *$ & -.01 & -.07 & -.02 & .04 & -.03 & .04 & .00 & -.08 & .01 & -.11 \\
\hline $\begin{array}{l}\text { 4. Health } \\
\text { outcomes }\end{array}$ & & & & -.09 & .01 & .04 & .00 & $-.21^{*}$ & -.04 & .03 & -.12 & -.02 & .16 \\
\hline 5. Avoid waste & & & & & .06 & -.02 & -.06 & -.12 & .01 & -.04 & -.08 & -.01 & -.12 \\
\hline $\begin{array}{l}\text { 6. Personal } \\
\text { characteristics }\end{array}$ & & & & & & -.11 & -.06 & -.07 & -.03 & -.01 & -.04 & -.01 & -.12 \\
\hline 7. Social norms & & & & & & & -.03 & -.08 & -.08 & $.18^{*}$ & -.10 & .10 & .01 \\
\hline 8. Closure & & & & & & & & -.05 & .05 & .06 & .13 & -.11 & -.10 \\
\hline 9. No difference & & & & & & & & & -.11 & -.11 & .10 & -.04 & -.10 \\
\hline $\begin{array}{l}\text { 10. Amount does } \\
\text { not matter }\end{array}$ & & & & & & & & & & .01 & $-.19 *$ & -.01 & .06 \\
\hline 11. Contingencies & & & & & & & & & & & .00 & -.10 & .03 \\
\hline $\begin{array}{l}\text { 12. General } \\
\text { comments }\end{array}$ & & & & & & & & & & & & -.08 & -.11 \\
\hline $\begin{array}{l}\text { 13. Reasoned } \\
\text { assumptions }\end{array}$ & & & & & & & & & & & & & -.06 \\
\hline 14. Advice & & & & & & & & & & & & & \\
\hline
\end{tabular}


Table 7

ANOVA statistics for coding categories

\begin{tabular}{|c|c|c|c|c|}
\hline Coding Category & $d f$ & $F$ & $p$ & $\overrightarrow{\eta_{p}}$ \\
\hline \multicolumn{5}{|l|}{ 1. Investment salience } \\
\hline Age** & 2 & 7.00 & .001 & .10 \\
\hline Expertise & 1 & .80 & .37 & .01 \\
\hline Age $\mathrm{X}$ expertise & 2 & .06 & .94 & .00 \\
\hline \multicolumn{5}{|l|}{ 2. Emotional salience* } \\
\hline Age** & 2 & 5.43 & .005 & .08 \\
\hline Expertise & 1 & .69 & .41 & .01 \\
\hline Age $\mathrm{X}$ expertise & 2 & 2.44 & .09 & .04 \\
\hline \multicolumn{5}{|l|}{ 3. Health outcomes* } \\
\hline Age & 2 & .12 & .88 & .00 \\
\hline Expertise & 1 & .91 & .34 & .01 \\
\hline Age $\mathrm{X}$ expertise & 2 & .03 & .97 & .00 \\
\hline \multicolumn{5}{|l|}{ 4. Avoid waste } \\
\hline Age & 2 & .43 & .65 & .01 \\
\hline Expertise & 1 & .27 & .61 & .00 \\
\hline Age $\mathrm{X}$ expertise & 2 & 2.24 & .11 & .04 \\
\hline \multicolumn{5}{|l|}{ 5. Personal characteristics } \\
\hline Age & 2 & .50 & .61 & .01 \\
\hline Expertise & 1 & .43 & .51 & .00 \\
\hline Age $\mathrm{X}$ expertise & 2 & .09 & .92 & .00 \\
\hline \multicolumn{5}{|l|}{ 6. Social norms* } \\
\hline Age & 2 & 1.74 & .18 & .03 \\
\hline Expertise & 1 & 1.77 & .19 & .01 \\
\hline Age $\mathrm{X}$ expertise & 2 & .42 & .66 & .01 \\
\hline \multicolumn{5}{|l|}{ 7. Closure* } \\
\hline Age & 2 & 1.44 & .24 & .02 \\
\hline Expertise & 1 & .18 & .67 & .01 \\
\hline Age $\mathrm{X}$ expertise & 2 & 1.48 & .23 & .02 \\
\hline \multicolumn{5}{|l|}{ 8. No difference* } \\
\hline Age & 2 & 1.78 & .17 & .03 \\
\hline Expertise & 1 & .39 & .53 & .00 \\
\hline Age $X$ expertise & 2 & .04 & .96 & .00 \\
\hline
\end{tabular}

\begin{tabular}{|c|c|c|c|c|}
\hline Coding Category & $d f$ & $F$ & $p$ & $\eta_{p}^{2}$ \\
\hline \multicolumn{5}{|l|}{ 1. Amount does not matter } \\
\hline $\mathrm{Age}^{* *}$ & 2 & 7.36 & .001 & .11 \\
\hline Expertise & 1 & .01 & .92 & .00 \\
\hline Age $\mathrm{X}$ expertise & 2 & .16 & .85 & .00 \\
\hline \multicolumn{5}{|l|}{ 2. Contingencies* } \\
\hline Age & 2 & 2.27 & .11 & .04 \\
\hline Expertise & 1 & .28 & .60 & .00 \\
\hline Age $\mathrm{X}$ expertise & 2 & 1.11 & .33 & .02 \\
\hline \multicolumn{5}{|l|}{ 3. General comments* } \\
\hline Age & 2 & 1.23 & .30 & .02 \\
\hline Expertise & 1 & 2.26 & .14 & .02 \\
\hline Age $\mathrm{X}$ expertise & 2 & .31 & .74 & .01 \\
\hline \multicolumn{5}{|l|}{ 4. Reasoned assumptions* } \\
\hline Age & 2 & .43 & .65 & .01 \\
\hline Expertise & 1 & 6.74 & .01 & .05 \\
\hline Age $\mathrm{X}$ expertise & 2 & .70 & .50 & .01 \\
\hline \multicolumn{5}{|l|}{ 5. Missing response* } \\
\hline Age & 2 & 2.01 & .14 & .03 \\
\hline Expertise & 1 & 3.77 & .05 & .03 \\
\hline Age $\mathrm{X}$ expertise & 2 & 2.01 & .14 & .03 \\
\hline \multicolumn{5}{|l|}{ 6. Offers of advice } \\
\hline Age & 2 & .78 & .46 & .01 \\
\hline Expertise & 1 & .19 & .6 & .00 \\
\hline Age $\mathrm{X}$ expertise & 2 & .37 & .69 & .01 \\
\hline \multicolumn{5}{|l|}{ 7. Other* } \\
\hline Age & 2 & 2.15 & .12 & .03 \\
\hline Expertise & 1 & 4.59 & .03 & .04 \\
\hline Age $\mathrm{X}$ expertise & 2 & 1.25 & .29 & .02 \\
\hline
\end{tabular}


Table 8

Significant MANOVA statistics for decision treatment, age, and expertise

\begin{tabular}{|c|c|c|c|c|}
\hline & $d f$ & $F$ & $p$ & $\eta_{p}^{2}$ \\
\hline \multicolumn{5}{|l|}{ Dessert } \\
\hline \multicolumn{5}{|l|}{ Decision treatment } \\
\hline Investment salience* & 1 & 145.56 & .000 & .55 \\
\hline Personal characteristics* & 1 & 6.71 & .01 & .05 \\
\hline \multicolumn{5}{|l|}{ Dinner } \\
\hline \multicolumn{5}{|l|}{ Decision treatment } \\
\hline Investment salience* & 1 & 32.74 & .000 & .22 \\
\hline Health outcomes* & 1 & 13.02 & .000 & .10 \\
\hline \multicolumn{5}{|l|}{ Age } \\
\hline Investment salience* & 1 & 4.75 & .01 & .08 \\
\hline Personal characteristics* & 1 & 4.97 & .01 & .08 \\
\hline \multicolumn{5}{|l|}{ Decision $\mathrm{x}$ age } \\
\hline Personal characteristics* & 1 & 4.78 & .01 & .08 \\
\hline \multicolumn{5}{|l|}{ Hobby Time } \\
\hline \multicolumn{5}{|l|}{ Decision } \\
\hline Investment salience* & 1 & 98.83 & .000 & .46 \\
\hline Emotional salience* & 1 & 19.56 & .000 & .15 \\
\hline Closure* & 1 & 4.82 & .030 & .04 \\
\hline No difference* & 1 & 7.23 & .01 & .06 \\
\hline Amount does not matter* & 1 & 10.91 & .001 & .09 \\
\hline \multicolumn{5}{|l|}{ Hobby Money } \\
\hline \multicolumn{5}{|l|}{ Decision } \\
\hline Investment salience* & 1 & 71.68 & .000 & .38 \\
\hline Emotional salience* & 1 & 8.95 & .003 & .07 \\
\hline No difference* & 1 & 6.37 & .01 & .05 \\
\hline \multicolumn{5}{|l|}{ Movie } \\
\hline \multicolumn{5}{|l|}{ Decision } \\
\hline Investment salience* & 1 & 48.07 & .000 & .29 \\
\hline Emotional salience* & 1 & 8.60 & .004 & .07 \\
\hline \multicolumn{5}{|l|}{ Age } \\
\hline Contingencies* & 1 & 4.81 & .01 & .08 \\
\hline \multicolumn{5}{|l|}{ Decision $\mathrm{x}$ age $\mathrm{x}$ expertise } \\
\hline Emotional salience* & 2 & 5.89 & .004 & .09 \\
\hline
\end{tabular}

Note. $*$ = significant Levene's test; $p<.025$ used to assess significance as recommended by Tabachnick and Fidell (2007). 
Table 9

Percentage of participants who demonstrated the SCF for each justification vignette pair

\begin{tabular}{lc}
\hline & $\%$ Demonstration \\
\hline Movie & $53.8 \%$ \\
DVD & $46.9 \%$ \\
Hobby money & $29.2 \%$ \\
Hobby time & $29.2 \%$ \\
Pay-per-view & $26.9 \%$ \\
Dessert & $23.1 \%$ \\
Writing & $20.0 \%$ \\
Concert & $17.7 \%$ \\
Meal & $16.9 \%$ \\
Dinner & $16.9 \%$ \\
Medicine & $14.6 \%$ \\
Healthclub & $14.6 \%$ \\
Fitness & $12.3 \%$ \\
\hline
\end{tabular}


Figure 1. Percentage of young, middle-aged, and older adults who indicated same or differently for the hobby time vignette pairs.

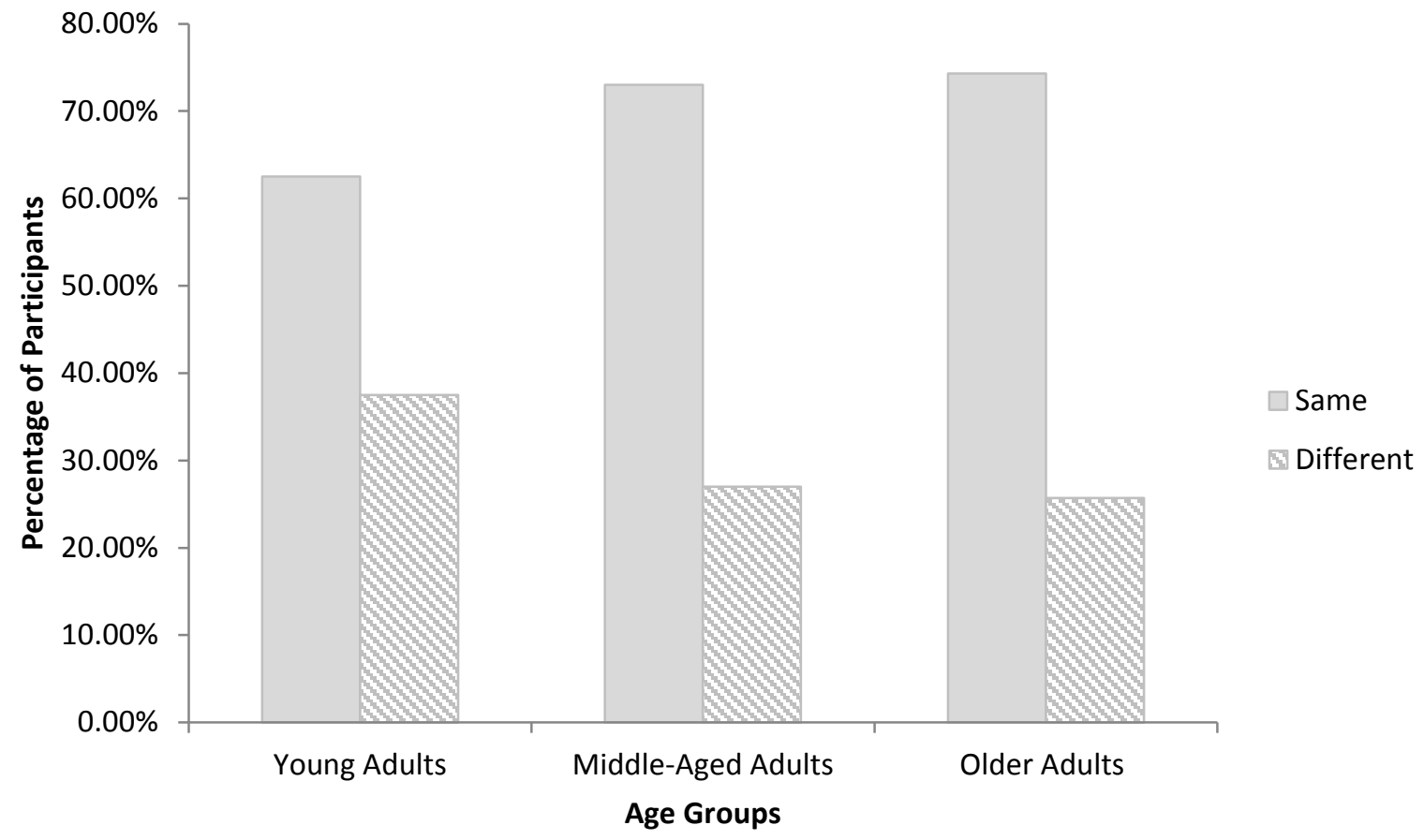


Figure 2. Percentage of young, middle-aged, and older adults who indicated same or differently for the hobby money vignette pairs.

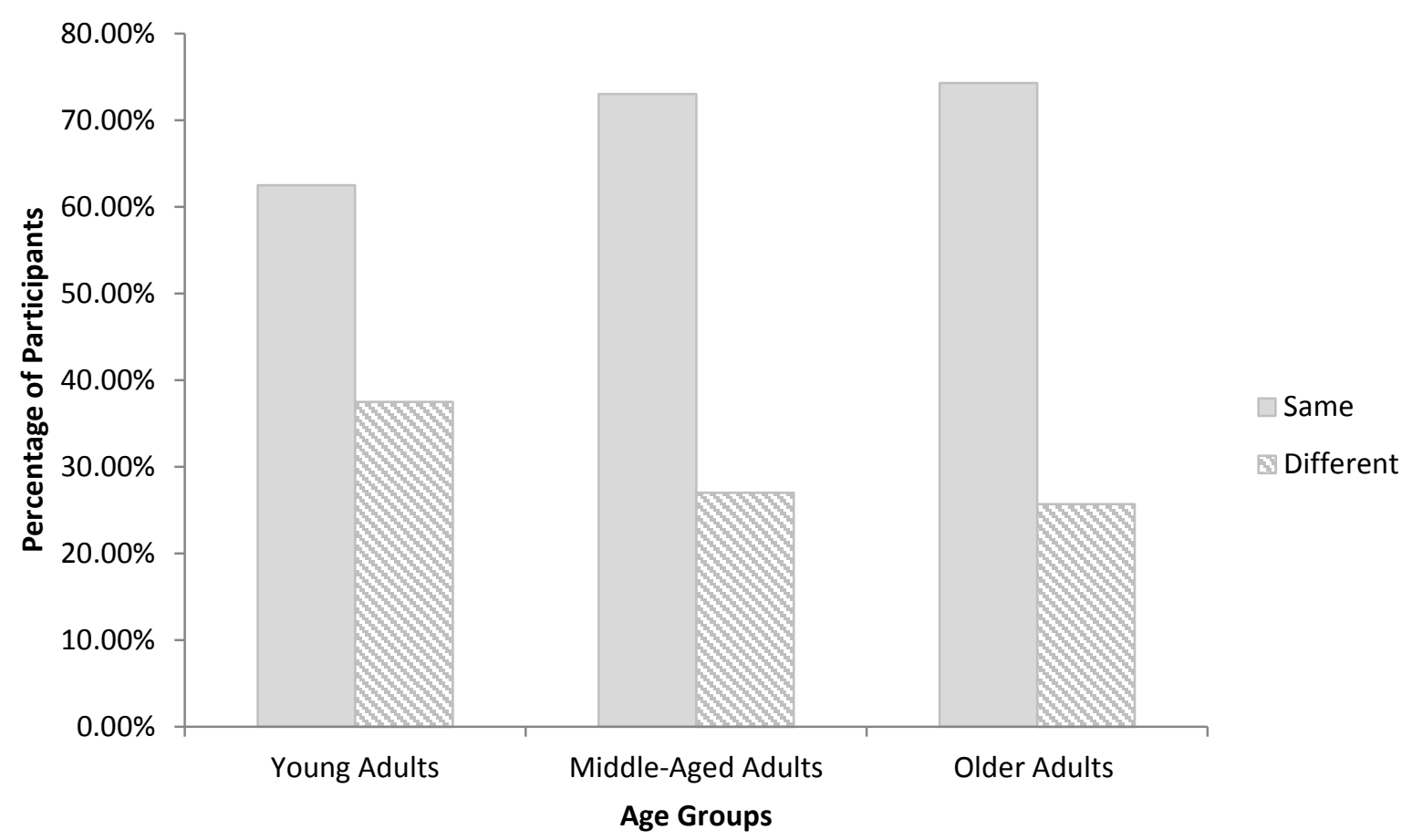


Figure 3. Percentage of young, middle-aged, and older adults who indicated same or differently for the dinner vignette pairs.

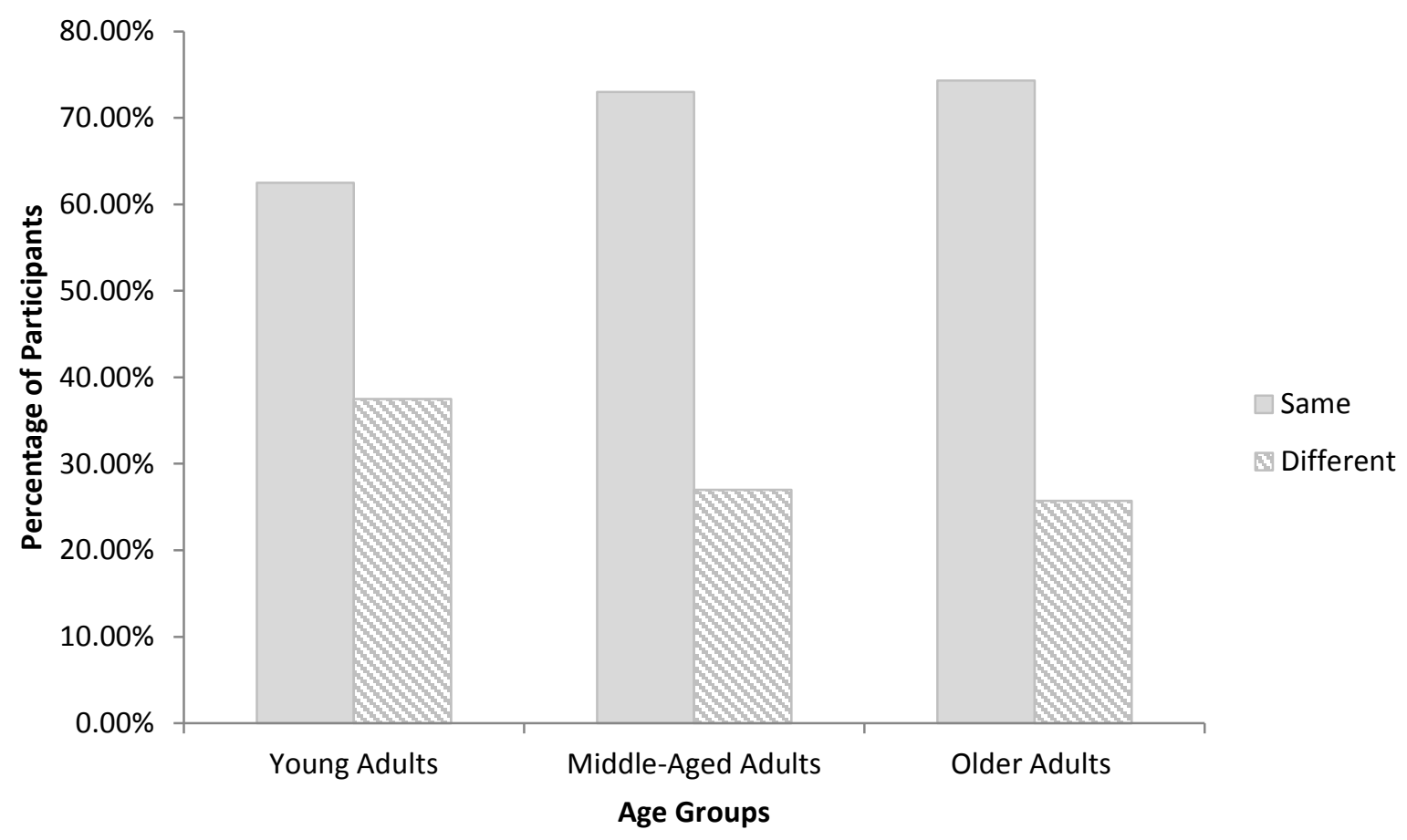


Figure 4. Percentage of young, middle-aged, and older adults who indicated same or differently for the movie vignette pairs.

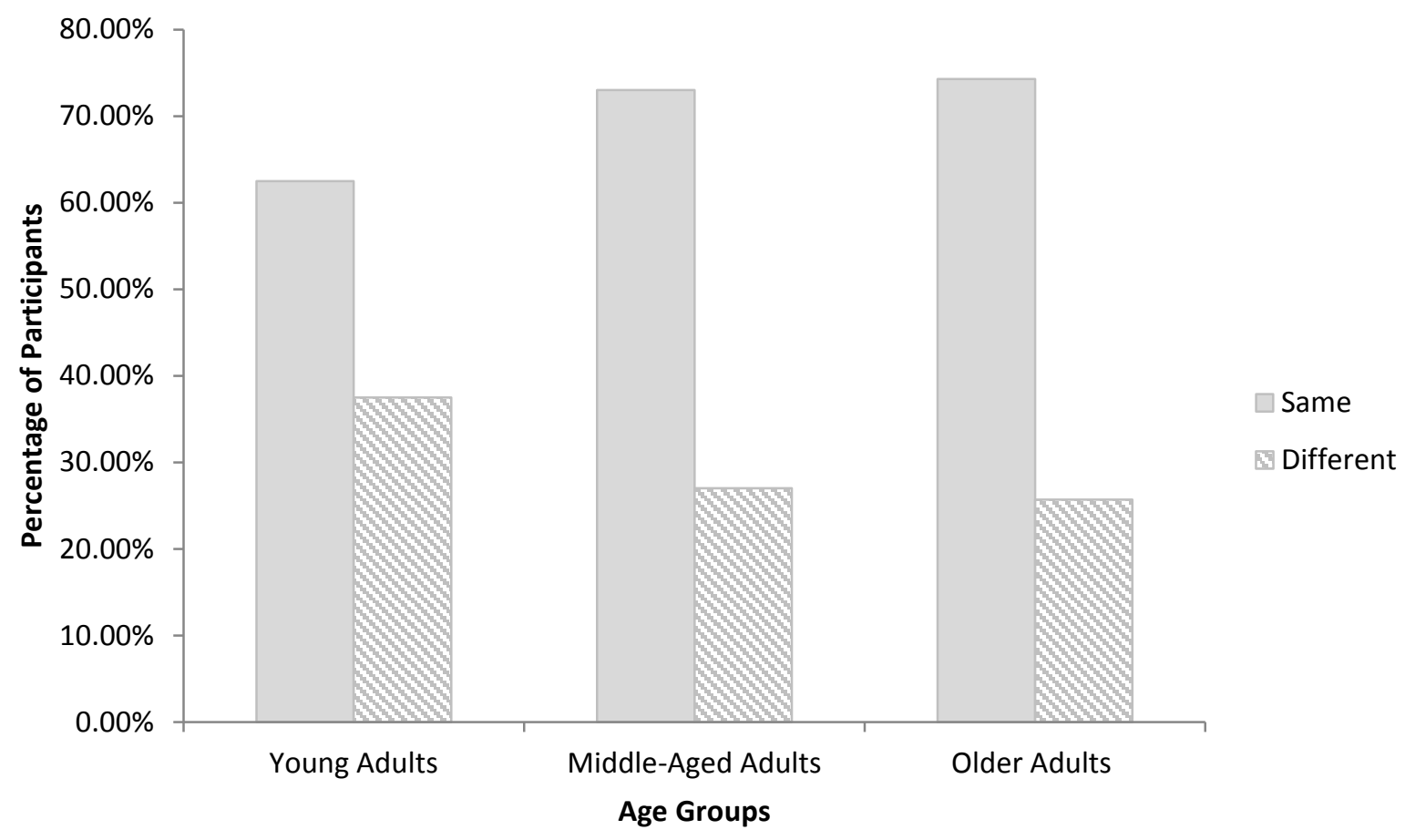


Figure 5. Percentage of young, middle-aged, and older adults who indicated same or differently for the dessert vignette pairs.

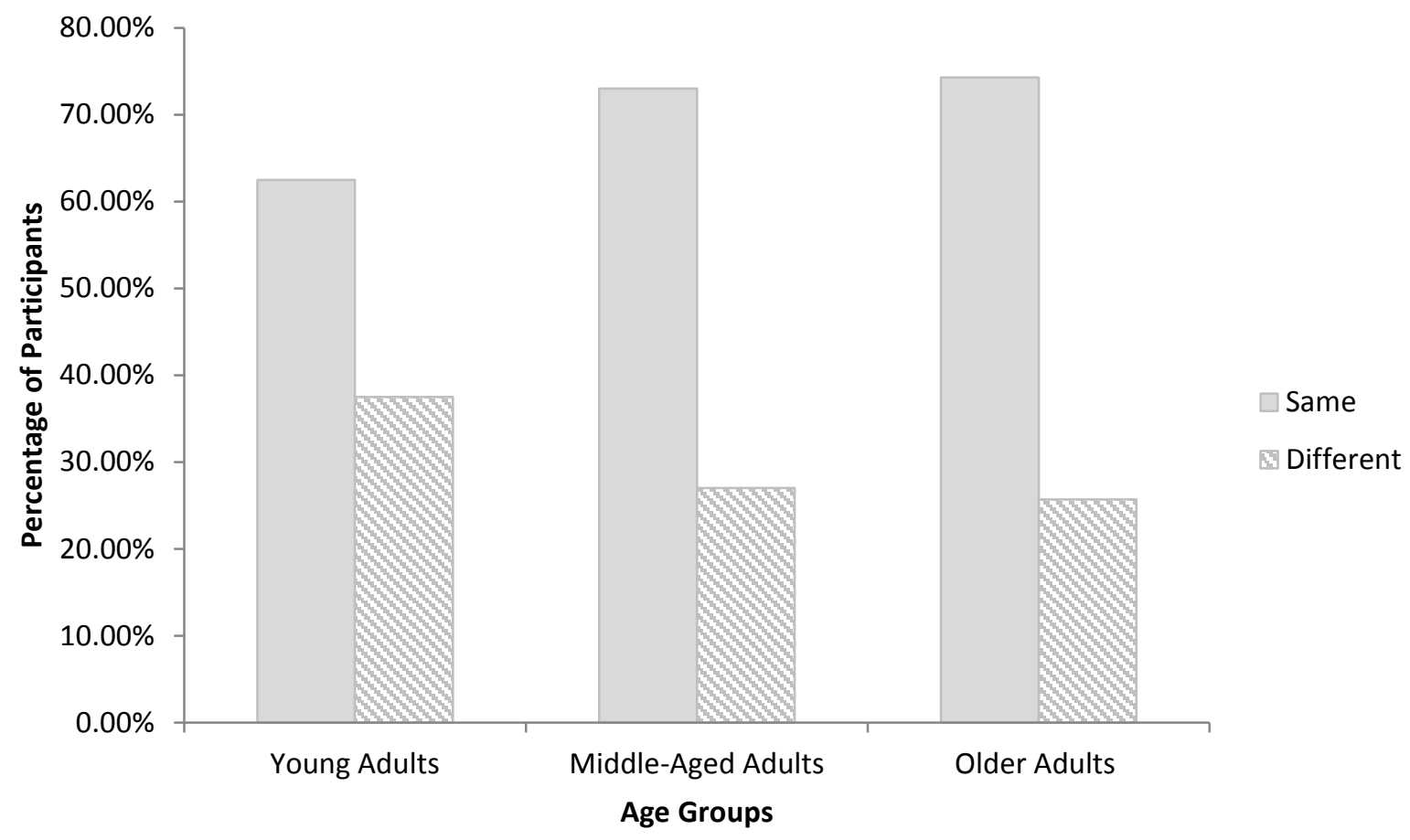




\section{Appendix A}

\section{Sunk-Cost Vignettes}

\section{Please read each vignette carefully. Think about each situation as you normally would and then select one option from the multiple choices.}

1a. You spent $\$ 42.00$ on a box of 7 frozen dinners. Two days later, you went to the doctor's office and learned that your cholesterol and blood pressure were too high. The doctor put you on a low-fat, low-sodium diet. The frozen dinners you bought are high in both sodium and fat. You must decide how many of the frozen dinners to eat.

Think about this situation as you normally would. Which of the following courses of action would you select?
a. do not eat any of the dinners
b. eat at least 1 of the dinners
c. eat at least 3 of the dinners
d. eat at least 5 of the dinners
e. eat all of the dinners

1b. You spent $\$ 7.00$ for a box of 7 frozen dinners. Two days later, you went to the doctor's office and learned that your cholesterol and blood pressure were too high. The doctor put you on a low-fat, low-sodium diet. The frozen dinners you bought are high in both sodium and fat. You must decide how many frozen dinners to eat.

Think about this situation as you normally would. Which of the following courses of action would you select?
a. do not eat any of the dinners
b. eat at least 1 of the dinners
c. eat at least 3 of the dinners
d. eat at least 5 of the dinners
e. eat all of the dinners 
2a. You paid $\$ 600.00$ for a 10 -week fitness and weight loss program. After five weeks, you still have not lost any weight and your fitness level seems the same. You are beginning to get discouraged. You must decide how much longer to follow the program.

Think about this situation as you normally would. Which of the following courses of action would you select?
a. stop the program altogether
b. stay on the program 2 more weeks
c. stay on the program 3 more weeks
d. stay on the program 4 more weeks
e. stay on the program until it ends

2b. You signed up for a 10-week fitness and weight loss program. After five weeks, you still have not lost any weight and your fitness level seems the same. You are beginning to get discouraged. You must decide how much longer to follow the program.

Think about this situation as you normally would. Which of the following courses of action would you select?
a. stop the program altogether
b. stay on the program 2 more weeks
c. stay on the program 3 more weeks
d. stay on the program 4 more weeks
e. stay on the program until it ends 
3a. You spent $\$ 59.99$ to watch your favorite team play a game against one of its biggest rivals on a pay-per-view sports channel. Your team is losing by a very large margin. There is another game on a different channel that you could watch instead. It is extremely unlikely your team will win. Watching your team lose always puts you in a bad mood. You must decide how much longer to continue to watch the game you paid for.

Think about this situation as you normally would. Which of the following courses of action would you select?
a. stop watching the game immediately
b. watch the game for 15 more minutes
c. watch the game for 30 more minutes
d. watch the game for 45 more minutes
e. watch the game until it ends

3b. You are watching your favorite team play a game against one of its biggest rivals on a sports channel. Your team is losing by a very large margin. There is another game on a different channel you could watch instead. It is extremely unlikely your team will win. Watching your team lose always puts you in a bad mood. You must decide how much longer to continue watching the game.

Think about this situation as you normally would. Which of the following courses of action would you select?
a. stop watching the game immediately
b. watch the game for 15 more minutes
c. watch the game for 30 more minutes
d. watch the game for 45 more minutes
e. watch the game until it ends 
4a. You paid $\$ 60.00$ for a ticket to a concert of your favorite music group. You have been waiting for the opening night of the show and are very excited to see it. A day before the concert, you realize that you have misplaced your ticket and you may have to buy another one. You are afraid that they will sell out. You must decide how long to wait to see if your ticket turns up before buying a new one.

Think about this situation as you normally would. Which of the following courses of action would you select?
a. buy a new ticket immediately
b. wait until the night before the concert
c. wait until the morning of the concert
d. wait until the afternoon of the concert
e. wait until you arrive at the concert to buy a new ticket

4b. You won a free ticket to a concert of your favorite music group because you were the $10^{\text {th }}$ person who called in on a radio show. You have been waiting for the opening night of the show and are very excited to see it. The day before the concert you realize that you have misplaced your ticket and you will have to buy another one. You are afraid that they will sell out. You must decide how long to wait to see if your ticket turns up before buying a new one.

Think about this situation as you normally would. Which of the following courses of action would you select?
a. buy a new ticket immediately
b. Wait until the night before the concert
c. wait until the morning of the concert
d. wait until the afternoon of the concert
e. wait until you arrive at the concert to buy a new ticket 
5a. You spent $\$ 80.00$ on ingredients to prepare 8 individual servings of your favorite meal. You replaced one of the ingredients you normally use with a substitute. You froze each serving separately, so you have enough for 8 meals. After thawing one of the servings to eat, you discovered the modified recipe didn't taste as good as the original. You must decide how many of the remaining 7 servings to eat.

Think about this situation as you normally would. Which of the following courses of action would you select?
a. do not eat any more of the servings of the meal
b. eat at least 1 more serving of the meal
c. eat at least 3 more servings of the meal
d. eat at least 5 more servings of the meal
e. finish eating all of the servings of the meal

5b. You prepared 8 individual servings of your favorite meal. You replaced one of the ingredients you normally use with a substitute. You froze each serving separately, so you have enough for 8 meals. After thawing one of the servings to eat, you discovered the modified recipe didn't taste as good as the original. You must decide how many of the remaining 7 servings to eat.

Think about this situation as you normally would. Which of the following courses of action would you select?
a. do not eat any more of the servings of the meal
b. eat at least 1 more serving of the meal
c. eat at least 3 more servings of the meal
d. eat at least 5 more servings of the meal
e. finish eating all of the servings of the meal 
6a. You pay $\$ 15.99$ for a cold medicine you don't usually take because the pharmacy is out of the usual brand you buy. After taking one dose of the medicine, you don't feel as well as you had hoped. You begin to wonder if the medicine is as effective as your usual brand. You must decide how long to wait to see whether the medicine will work.

Think about this situation as you normally would. Which of the following courses of action would you select?
a. stop waiting immediately and try something else
b. wait 15 more minutes to see if the medicine will start to work
c. wait 30 more minutes to see if the medicine will start to work
d. wait 45 more minutes to see if the medicine will start to work
e. take the next dose of the medicine at the recommended time and keep using it until you feel well or run out of doses, whichever comes first

6b. You take a cold medicine you don't usually take because the pharmacy is out of the usual brand you buy. After taking one dose of the medicine, you don't feel as well as you had hoped. You begin to wonder if the medicine is as effective as your usual brand. You must decide how long to wait to see whether the medicine will work.

Think about this situation as you normally would. Which of the following courses of action would you select?

a. stop waiting immediately and try something else

b. wait 15 more minutes to see if the medicine will start to work

c. wait 30 more minutes to see if the medicine will start to work

d. wait 45 more minutes to see if the medicine will start to work

e. take the next dose of the medicine at the recommended time and keep using it until you feel well or run out of doses, whichever comes first 
7a. You paid $\$ 75.00$ for a collector's edition of a film on DVD. After watching it for 10 minutes, you are disappointed with the quality of the film. You must decide how much longer to continue watching the film.

Think about this situation as you normally would. Which of the following courses of action would you select?
a. stop watching entirely
b. watch for 10 more minutes
c. watch for 15 more minutes
d. watch for 20 more minutes
e. watch until the end

7b. You paid 25 cents for a collector's edition of a film on DVD. After watching it for 10 minutes, you are disappointed with the quality of the film. You must decide how much longer to continue watching the film.

Think about this situation as you normally would. Which of the following courses of action would you select?
a. stop watching entirely
b. watch for 10 more minutes
c. watch for 15 more minutes
d. watch for 20 more minutes
e. watch until the end 
8a. You spent $\$ 250.00$ on supplies for a project related to one of your hobbies. Lately, you have lost interest in the project. Whenever you work on the project, you are bored and wish that you were doing something else. You have been thinking about starting a new project instead. You must decide what to do about the project.

Think about this situation as you normally would. Which of the following courses of action would you select?
a. stop working on the project altogether
b. wait for a couple of weeks to see if interest in the project increases
c. wait for a month or two to see if interest in the project increases
d. wait for six months to see if interest in the project increases
e. remain committed to the project

8b. You have been working on a project related to one of your hobbies. Lately, you have lost interest in the project. Whenever you work on the project, you are bored and wish that you were doing something else. You have been thinking about starting a new project instead. You must decide what to do about the project.

Think about this situation as you normally would. Which of the following courses of action would you select?
a. stop working on the project altogether
b. wait for a couple of weeks to see if interest in the project increases
c. wait for a month or two to see if interest in the project increases
d. wait for six months to see if interest in the project increases
e. remain committed to the project 
9a. You are staying in a hotel room on vacation. You paid \$10.95 to see a movie on pay TV. After 5 minutes, you are bored and the movie seems pretty bad. How much longer would you continue to watch the movie?

Think about this situation as you normally would. Which of the following courses of action would you select?
a. stop watching entirely
b. watch for 10 more minutes
c. watch for 20 more minutes
d. watch for 30 more minutes
e. watch until the end

9b. You are staying in a hotel room on vacation. You turn on the TV and there is a movie on. After 5 minutes, you are bored and the movie seems pretty bad. How much longer would you continue to watch the movie?

Think about this situation as you normally would. Which of the following courses of action would you select?
a. stop watching entirely
b. watch for 10 more minutes
c. watch for 20 more minutes
d. watch for 30 more minutes
e. watch until the end 
10a. You order your favorite frozen dessert for $\$ 12.95$ after your dinner at a nice restaurant. It is wonderful but very rich, and after two bites you find you are very full. How much more of the dessert would you eat?

Think about this situation as you normally would. Which of the following courses of action would you select?
a. do not eat any more of the dessert
b. eat $1 / 4$ of the dessert
c. eat $1 / 2$ of the dessert
d. eat $3 / 4$ of the dessert
e. eat the dessert until it is gone

10b. You order your favorite frozen dessert after you dinner at a nice restaurant. Your waiter tells you the dessert is free because it is the restaurant's one year anniversary. It is wonderful but very rich, and after two bites you find you are very full. You must decide how much more of the dessert to eat.

Think about this situation as you normally would. Which of the following courses of action would you select?
a. do not eat any more of the dessert
b. eat $1 / 4$ of the dessert
c. eat $1 / 2$ of the dessert
d. eat 3/4 of the dessert
e. eat the dessert until it is gone 
11a. For 1 month you have been working on a project related to one of your hobbies. Lately, you have lost interest in the project. Whenever you work on the project, you are bored and wish that you were doing something else.

Think about this situation as you normally would. Which of the following courses of action would you select?
a. stop working on the project altogether
b. wait for a couple of weeks to see if interest in the project increases
c. wait for a month or two to see if interest in the project increases
d. wait for six months to see if interest in the project increases
e. remain committed to the project

11b. For 5 years, you have been working on a project related to one of your hobbies. Lately, you have lost interest in the project. Whenever you work on the project, you are bored and wish that you were doing something else.

Think about this situation as you normally would. Which of the following courses of action would you select?
a. stop working on the project altogether
b. wait for a couple of weeks to see if interest in the project increases
c. wait for a month or two to see if interest in the project increases
d. wait for six months to see if interest in the project increases
e. remain committed to the project 
12a. You paid $\$ 400.00$ for a membership at a health club and the membership includes 4 lessons for an activity of your choice. You develop an injury that would make it extremely painful to take the lessons. You must decide how many lessons to take before your membership expires.

Think about this situation as you normally would. Which of the following courses of action would you select?
a. do not take any lessons
b. take 1 lesson
c. take 2 lessons
d. take 3 lessons
e. take all of the lessons

12b. You won a free membership at a health club and the membership includes 4 free lessons for an activity of your choice. You develop an injury that would make it extremely painful to take the lessons. You must decide how many lessons to take before your membership expires.

Think about this situation as you normally would. Which of the following courses of action would you select?
a. do not take any lessons
b. take 1 lesson
c. take 2 lessons
d. take 3 lessons
e. take all of the lessons 
13a. For the past 45 minutes you have been writing to your best friend detailing a story that happened to you recently. You suddenly realize that if you had told the story another way it would have been funnier and easier to understand. It will take you about 20 more minutes to finish the story you already started. You must decide how much longer to spend writing the story.

Think about this situation as you normally would. Which of the following courses of action would you select?
a. stop writing the letter immediately and start over
b. write for 5 more minutes
c. write for 10 more minutes
d. write for 15 more minutes
e. finish the entire letter

13b. For the past 5 minutes you have been writing to your best friend detailing a story that happened to you recently. You suddenly realize that if you had told the story another way it would have been funnier and easier to understand. It will take you about 20 more minutes to finish the story you already started. You must decide how much longer to keep working on the story.

Think about this situation as you normally would. Which of the following courses of action would you select?
a. stop writing the letter immediately and start over
b. write for 5 more minutes
c. write for 10 more minutes
d. write for 15 more minutes
e. finish the entire letter 


\section{Appendix B}

\section{Judgment and Decision Questions}

1. Imagine that recent evidence has shown that a pesticide is threatening the lives of 1,200 endangered animals. Two response options have been suggested:

If Option A is used, 600 animals will be saved for sure.

If Option B is used, there is a $75 \%$ chance that 800 animals will be saved, and a $25 \%$ chance that no animals will be saved.

Which option do you recommend to use?

$\begin{array}{cccccc}1 & 2 & 3 & 4 & 5 & 6 \\ \begin{array}{c}\text { Definitely would } \\ \text { choose A }\end{array} & & & & \begin{array}{c}\text { Definitely would } \\ \text { choose B }\end{array}\end{array}$

2. Because of changes in tax laws, you may get back as much as $\$ 1200$ in income tax. Your accountant has been exploring alternative ways to take advantage of this situation. He has developed two plans:

If Plan A is adopted, you will get back $\$ 400$ of the possible $\$ 1200$.

If Plan B is adopted, you have a 33\% chance of getting back all $\$ 1200$, and a $67 \%$ chance of getting back no money.

Which plan would you use?

$\begin{array}{cccccc}1 & 2 & 3 & 4 & 5 & 6 \\ \begin{array}{c}\text { Definitely would } \\ \text { choose A }\end{array} & & & & \begin{array}{c}\text { Definitely would } \\ \text { choose B }\end{array}\end{array}$

3. Imagine that in one particular state it is projected that 1000 students will drop out of school during the next year. Two programs have been proposed to address this problem, but only one can be implemented. Based on other states' experiences with the programs, estimates of the outcomes that can be expected from each program can be made. Assume for purposes of this decision that these estimates of the outcomes are accurate and are as follows:

If Program A is adopted, 400 of the 1000 students will stay in school.

If Program B is adopted, there is a $40 \%$ chance that all 1000 students will stay in school and $60 \%$ chance that none of the 1000 students will stay in school.

Which program would you favor for implementation? 


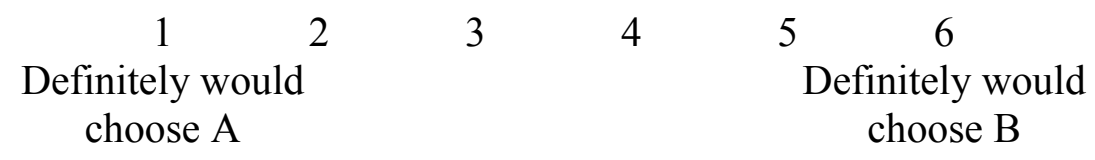

4. Imagine that the U.S. is preparing for the outbreak of an unusual disease, which is expected to kill 600 people. Two alternative programs to combat the disease have been proposed. Assume that the exact scientific estimates of the consequences of the programs are as follows:

If Program A is adopted, 200 people will be saved.

If Program B is adopted, there is a $33 \%$ chance that 600 people will be saved, and a $67 \%$ chance that no people will be saved.

Which program do you recommend to use?

$\begin{array}{cccccc}1 & 2 & 3 & 4 & 5 & 6 \\ \begin{array}{c}\text { Definitely would } \\ \text { choose A }\end{array} & & & & \begin{array}{c}\text { Definitely would } \\ \text { choose B }\end{array}\end{array}$

5. Imagine that your doctor tells you that you have a cancer that must be treated. Your choices are as follows:

Surgery: Of 100 people having surgery, 90 live through the operation, and 34 are alive at the end of five years.

Radiation therapy: Of 100 people having radiation therapy, all live through the treatment, and 22 are alive at the end of five years.

Which treatment would you choose?

$\begin{array}{cllll}1 \quad 2 & 3 & 4 & 5 & 6 \\ \begin{array}{c}\text { Definitely would } \\ \text { choose surgery }\end{array} & & & & \begin{array}{c}\text { Definitely would } \\ \text { choose radiation }\end{array}\end{array}$

6. Imagine that your client has $\$ 6,000$ invested in the stock market. A downturn in the economy is occurring. You have two investment strategies that you can recommend under the existing circumstances to preserve your client's capital.

If strategy A is followed, $\$ 2,000$ of your client's investment will be saved.

If strategy B is followed, there is a $33 \%$ chance that the entire $\$ 6,000$ will be saved, and a $67 \%$ chance that none of the principal will be saved.

Which of these two strategies would you favor? 


$\begin{array}{cccccc}1 & 2 & 3 & 4 & 5 & 6 \\ \begin{array}{c}\text { Definitely would } \\ \text { choose A }\end{array} & & & & \begin{array}{c}\text { Definitely would } \\ \text { choose B }\end{array}\end{array}$

7. Imagine a hospital is treating 32 injured soldiers, who are all expected to lose one leg. There are two doctors that can help the soldiers, but only one can be hired:

If Doctor A is hired, 20 soldiers will keep both legs.

If Doctor B is hired, there is a $63 \%$ chance that all soldiers keep both legs and a $37 \%$ chance that nobody will save both legs.

Which doctor do you recommend?

$\begin{array}{cccccc}1 \quad 2 & 3 & 4 & 5 & 6 \\ \begin{array}{c}\text { Definitely would } \\ \text { choose A }\end{array} & & & & \begin{array}{c}\text { Definitely would } \\ \text { choose B }\end{array}\end{array}$

8. Imagine that a type of condom has a $95 \%$ success rate. That is, if you have sex with someone who has the AIDS virus, there is a $95 \%$ chance that this type of condom will prevent you from being exposed to the AIDS virus.

Should the government allow this type of condom to be advertised as "an effective method for lowering the risk of AIDS?"

$\begin{array}{cccccc}1 & 2 & 3 & 4 & 5 & 6 \\ \text { Definitely no } & & & & & \text { Definitely yes }\end{array}$

9. Imagine the following situation. You are entertaining a special friend by inviting them for dinner. You are making your favorite lasagna dish with ground beef. Your roommate goes to the grocery store and purchases a package of ground beef for you. The label says $80 \%$ lean ground beef.

What's your evaluation of the quality of this ground beef?

$\begin{array}{cccccc}1 & 2 & 3 & 4 & 5 & \begin{array}{c}6 \\ \text { Very low }\end{array} \\ & & & & \text { Very high }\end{array}$

10. In a recent confidential survey completed by graduating seniors, $35 \%$ of those completing the survey stated that they had never cheated during their college career.

Considering the results of the survey, how would you rate the incidence of cheating at your university?

$\begin{array}{cccccc}1 & 2 & 3 & 4 & 5 & \begin{array}{c}6 \\ \text { Very low }\end{array} \\ & & & & \text { Very high }\end{array}$


11. As R\&D manager, one of your project teams has come to you requesting an additional $\$ 100,000$ in funds for a project you instituted several months ago. The project is already behind schedule and over budget, but the team still believes it can be successfully completed. You currently have $\$ 500,000$ remaining in your budget unallocated, but which must carry you for the rest of the fiscal year. Lowering the balance by an additional $\$ 100,000$ might jeopardize flexibility to respond to other opportunities.

Evaluating the situation, you believe there is a fair chance the project will not succeed, in which case the additional funding would be lost; if successful, however, the money would be well spent. You also noticed that of the projects undertaken by this team, 30 of the last 50 have been successful.

What is the likelihood you would fund the request?

$\begin{array}{cccccc}1 & 2 & 3 & 4 & 5 & 6 \\ \text { Very unlikely } & & & & & \text { Very likely }\end{array}$

12. Suppose a student got $90 \%$ correct in the mid-term exam and $70 \%$ correct in the finalterm exam, what would be your evaluations of this student's performance?

$\begin{array}{cccccc}1 & 2 & 3 & 4 & 5 & 6 \\ \text { Very poor } & & & & & \text { Very good }\end{array}$

13. Imagine that a woman parked illegally. After talking to her, you believe that there is a $20 \%$ chance that she did not know she parked illegally.

With this in mind, how much of a fine do you believe this woman deserves?

$\begin{array}{lllllc}1 & 2 & 3 & 4 & 5 & 6 \\ \text { Minimum fine } & & & & & \text { Maximum fine }\end{array}$

14. Imagine that a new technique has been developed to treat a particular kind of cancer. This technique has a 50\% chance of success, and is available at the local hospital.

A member of your immediate family is a patient at the local hospital with this kind of cancer. Would you encourage him or her to undergo treatment using this technique?

$\begin{array}{cccccc}1 & 2 & 3 & 4 & 5 & 6 \\ \text { Definitely no } & & & & & \text { Definitely yes }\end{array}$

15. Imagine a hospital is treating 32 injured soldiers, who are all expected to lose one leg. There are two doctors that can help the soldiers, but only one can be hired:

If Doctor A is hired, 12 soldiers will lose one leg. 
If Doctor B is hired, there is a $63 \%$ chance that nobody loses a leg and a $37 \%$ chance that all lose a leg.

Which doctor do you recommend?

$\begin{array}{cccccc}1 & 2 & 3 & 4 & 5 & 6 \\ \begin{array}{c}\text { Definitely would } \\ \text { choose A }\end{array} & & & & \begin{array}{c}\text { Definitely would } \\ \text { choose B }\end{array}\end{array}$

16. Imagine that the U.S. is preparing for the outbreak of an unusual disease, which is expected to kill 600 people. Two alternative programs to combat the disease have been proposed. Assume that the exact scientific estimates of the consequences of the programs are as follows:

If Program A is adopted, 400 people will die.

If Program B is adopted, there is a $33 \%$ chance that nobody will die, and a $67 \%$ chance that 600 people will die.

Which program do you recommend to use?

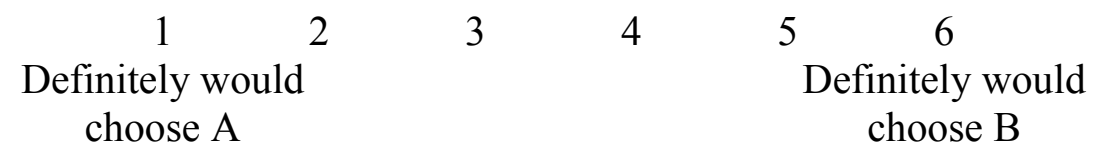

17. Imagine that your client has $\$ 6,000$ invested in the stock market. A downturn in the economy is occurring. You have two investment strategies that you can recommend under the existing circumstances to preserve your client's capital.

If strategy A is followed, $\$ 4,000$ of your client's investment will be lost.

If strategy $\mathrm{B}$ is followed, there is a $33 \%$ chance that the nothing will be lost, and a $67 \%$ chance that $\$ 6,000$ will be lost.

Which of these two strategies would you favor?

$\begin{array}{cccccc}1 & 2 & 3 & 4 & 5 & 6 \\ \begin{array}{c}\text { Definitely would } \\ \text { choose A }\end{array} & & & & \text { Definitely would } \\ \text { choose B }\end{array}$

18. Because of changes in tax laws, you may get back as much as $\$ 1200$ in income tax. Your accountant has been exploring alternative ways to take advantage of this situation. He has developed two plans:

If Plan A is adopted, you will lose $\$ 800$ of the possible $\$ 1200$. 
If Plan B is adopted, you have a 33\% chance of losing none of the money, and a $67 \%$ chance of losing all $\$ 1200$.

Which plan would you use?

$\begin{array}{cccccc}1 & 2 & 3 & 4 & 5 & 6 \\ \begin{array}{c}\text { Definitely would } \\ \text { choose A }\end{array} & & & & \begin{array}{c}\text { Definitely would } \\ \text { choose B }\end{array}\end{array}$

19. Imagine that recent evidence has shown that a pesticide is threatening the lives of 1,200 endangered animals. Two response options have been suggested:

If Option $\mathrm{A}$ is used, 600 animals will be lost for sure.

If Option B is used, there is a $75 \%$ chance that 400 animals will be lost, and a $25 \%$ chance that 1,200 animals will be lost.

Which option do you recommend to use?



20. Imagine that your doctor tells you that you have a cancer that must be treated. Your choices are as follows:

Surgery: Of 100 people having surgery, 10 die because of the operation, and 66 die by the end of five years.

Radiation therapy: Of 100 people having radiation therapy, none die during the treatment, and 78 die by the end of five years.

Which treatment would you choose?

$\begin{array}{cllll}1 \quad 2 & 3 & 4 & 5 & 6 \\ \begin{array}{c}\text { Definitely would } \\ \text { choose surgery }\end{array} & & & & \begin{array}{l}\text { Definitely would } \\ \text { choose radiation }\end{array}\end{array}$

21. Imagine that in one particular state it is projected that 1000 students will drop out of school during the next year. Two programs have been proposed to address this problem, but only one can be implemented. Based on other states' experiences with the programs, estimates of the outcomes that can be expected from each program can be made. Assume for purposes of this decision that these estimates of the outcomes are accurate and are as follows:

If Program A is adopted, 600 of the 1000 students will drop out of school. 
If Program B is adopted, there is a $40 \%$ chance that none of the 1000 students will drop out of school and $60 \%$ chance that all 1000 students will drop out of school.

Which program would you favor for implementation?

$\begin{array}{cccccc}1 & 2 & 3 & 4 & 5 & 6 \\ \begin{array}{c}\text { Definitely would } \\ \text { choose A }\end{array} & & & & \begin{array}{c}\text { Definitely would } \\ \text { choose B }\end{array}\end{array}$

22. As R\&D manager, one of your project teams has come to you requesting an additional $\$ 100,000$ in funds for a project you instituted several months ago. The project is already behind schedule and over budget, but the team still believes it can be successfully completed. You currently have $\$ 500,000$ remaining in your budget unallocated, but which must carry you for the rest of the fiscal year. Lowering the balance by an additional $\$ 100,000$ might jeopardize flexibility to respond to other opportunities.

Evaluating the situation, you believe there is a fair chance the project will not succeed, in which case the additional funding would be lost; if successful, however, the money would be well spent. You also noticed that of the projects undertaken by this team, 20 of the last 50 have been unsuccessful.

What is the likelihood you would fund the request?

$\begin{array}{cccccc}1 & 2 & 3 & 4 & 5 & 6 \\ \text { Very unlikely } & & & & & \text { Very likely }\end{array}$

23. Imagine that a woman parked illegally. After talking to her, you believe that there is an $80 \%$ chance that she knew she parked illegally.

With this in mind, how much of a fine do you believe this woman deserves?

$\begin{array}{cccccc}1 & 2 & 3 & 4 & 5 & 6 \\ \text { Minimum fine } & & & & & \text { Maximum fine }\end{array}$

24. In a recent confidential survey completed by graduating seniors, $65 \%$ of those completing the survey stated that they had cheated during their college career.

Considering the results of the survey, how would you rate the incidence of cheating at your university?

$\begin{array}{cccccc}1 & 2 & 3 & 4 & 5 & 6 \\ \text { Very low } & & & & & \text { Very high }\end{array}$

25. Imagine that a new technique has been developed to treat a particular kind of cancer. This technique has a 50\% chance of failure, and is available at the local hospital. 
A member of your immediate family is a patient at the local hospital with this kind of cancer. How likely are you to encourage him or her to undergo treatment using this technique?

$\begin{array}{cccccc}1 & 2 & 3 & 4 & 5 & 6 \\ \text { Definitely no } & & & & & \text { Definitely yes }\end{array}$

26. Imagine the following situation. You are entertaining a special friend by inviting them for dinner. You are making your favorite lasagna dish with ground beef. Your roommate goes to the grocery store and purchases a package of ground beef for you. The label says $20 \%$ fat ground beef.

What's your evaluation of the quality of this ground beef?

$\begin{array}{cccccc}1 & 2 & 3 & 4 & 5 & 6 \\ \text { Very low } & & & & & \text { Very high }\end{array}$

27. Imagine that a type of condom has a 5\% failure rate. That is, if you have sex with someone who has the AIDS virus, there is a 5\% chance that this type of condom will fail to prevent you from being exposed to the AIDS virus.

Should the government allow this type of condom to be advertised as "an effective method for lowering the risk of AIDS?"

$\begin{array}{cccccc}1 & 2 & 3 & 4 & 5 & 6 \\ \text { Definitely no } & & & & & \text { Definitely yes }\end{array}$

28. Suppose a student got $10 \%$ incorrect in the mid-term exam and $30 \%$ incorrect in the final-term exam, what would be your evaluations of this student's performance?

$\begin{array}{lllllc}1 & 2 & 3 & 4 & 5 & 6 \\ \text { Very poor } & & & & & \text { Very good }\end{array}$




\section{Appendix C}

Justifications

Please read the situations and decide whether you think the situations should be treated the same way or whether you think they should be treated differently. Provide enough evidence to support your answer so that if someone were to question your reasoning you would have plentiful support.

1. After dinner at a nice restaurant, you order your favorite dessert for $\$ 12.95$. It is wonderful but very rich, and after two bites you find you are very full. How much more of the dessert would you eat?

After dinner at a nice restaurant, you order your favorite dessert. Your waiter tells you the dessert is free because it is the restaurant's one year anniversary. It is wonderful but very rich, and after two bites you find you are very full. How much more of the dessert would you eat?

A) Should these vignettes be treated the same or differently?

Same

Differently

A1) If they should be treated differently, why?

A2) If they should be treated the same, why?

2. You paid $\$ 10.95$ to see a movie on pay TV. After 5 minutes, you are bored and the movie seems pretty bad. How much longer would you continue to watch the movie?

You turn on the TV and there is a movie on. After 5 minutes, you are bored and the movie seems pretty bad. How much longer would you continue to watch the movie?

A) Should these vignettes be treated the same or differently?

Same Differently

A1) If they should be treated differently, why?

A2) If they should be treated the same, why? 
3. You spent $\$ 42.00$ on a box of 7 frozen dinners. Two days later, you went to the doctor's office and learned that your cholesterol and blood pressure were too high. The doctor put you on a low-fat, low-sodium diet. The frozen dinners you bought are high in both sodium and fat. You must decide how many of the frozen dinners to eat.

You spent $\$ 7.00$ for a box of 7 frozen dinners. Two days later, you went to the doctor's office and learned that your cholesterol and blood pressure were too high. The doctor put you on a low-fat, low-sodium diet. The frozen dinners you bought are high in both sodium and fat. You must decide how many frozen dinners to eat.

A) Should these vignettes be treated the same or differently?

Same

Differently

A1) If they should be treated differently, why?

A2) If they should be treated the same, why?

4. For 5 years, you have been working on a project related to one of your hobbies. Lately, you have lost interest in the project. Whenever you work on the project, you are bored and wish that you were doing something else.

For 1 month you have been working on a project related to one of your hobbies. Lately, you have lost interest in the project. Whenever you work on the project, you are bored and wish that you were doing something else.

A) Should these vignettes be treated the same or differently?

Same

Differently

A1) If they should be treated differently, why?

A2) If they should be treated the same, why? 
5. You spent $\$ 250.00$ on supplies for a project related to one of your hobbies. Lately, you have lost interest in the project. Whenever you work on the project, you are bored and wish that you were doing something else. You have been thinking about starting a new project instead. You must decide what to do about the project.

You have been working on a project related to one of your hobbies. Lately, you have lost interest in the project. Whenever you work on the project, you are bored and wish that you were doing something else. You have been thinking about starting a new project instead. You must decide what to do about the project.

A) Should these vignettes be treated the same or differently?
Same
Differently

A1) If they should be treated differently, why?

A2) If they should be treated the same, why? 


\section{Appendix D}

\section{Decision Outcomes Inventory}

In the last 10 years, have you ever...

1. a. Rented a movie

b. Returned a movie you rented without having watched it at all

2. a. Bought new clothes or shoes

b. Bought new clothes or shoes you never wore

3. a. Gone shopping for food or groceries

b. Threw out food or groceries you had bought because they went bad

4. a. Done your own laundry

b. Ruined your clothes because you didn't follow the laundry instructions on the label

5. a. Been enrolled in any kind of school

b. Been suspended from school for at least one day for any reason

6. a. Had any kind of job

b. Quit a job after a week

7. a. Had a driver's license

b. Had your driver's license taken away from you by the police

8. a. Driven a car

b. Been accused of causing a car accident while driving

c. Gotten more than 5 parking tickets

d. Gotten more than 5 speeding tickets

e. Gotten lost or gone the wrong way for more than 10 minutes while driving

f. Locked your keys in the car

9. a. Bought any kind of car

b. Had to spend at least $\$ 500$ to fix a car you had owned for less than half a year

10. a. Taken a trip by airplane

b. Missed a flight

11. a. Taken the train or the bus

b. Taken the wrong train or bus

12. a. Had any form of ID (driver's license, passport, birth certificate)

b. Had your ID replaced because you lost it

13. a. Lived in a rented apartment or other rental property

b. Been kicked out of an apartment or rental property before the lease ran out

14. a. Carried a key to your home

b. Had the key to your home replaced because you lost it

c. Locked yourself out of your home

15. a. Been responsible for electricity, cable, gas or water payments

b. Had your electricity, cable, gas or water shut off because you didn't pay on time

16. a. Been responsible for a mortgage or loan

b. Foreclosed a mortgage or loan

17. a. Been responsible for rent or mortgage payments

b. Paid a rent or mortgage payment at least 2 weeks too late

18. a. Used checks 
b. Had a check bounce

19. a. Had a credit card

b. Had more than $\$ 5,000$ in credit card debt

20. a. Invested in the stock market

b. Lost more than $\$ 1,000$ on a stock market investment

21. a. Been to a bar, restaurant, or hotel

b. Been kicked out of a bar, restaurant, or hotel by someone who works there

22. a. Loaned more than $\$ 50$ to someone

b. Loaned more than $\$ 50$ to someone and never got it back

23. a. Had a romantic relationship that lasted for at least 1 year

b. Cheated on your romantic partner of 1 year by having sex with someone else

24. a. Been married

b. Been divorced

25. a. Had sex

b. Been diagnosed with an STD

c. Had an unplanned pregnancy (or got someone pregnant, unplanned)

26. a. Had sex with a condom

b. Had a condom break, tear, or slip off

27. a. Had an alcoholic drink

b. Consumed so much alcohol you vomited

c. Received a DUI for drunk driving

28. a. Been out in the sun

b. Got blisters from sunburn

29. Been in a jail cell overnight for any reason

30. Been in a public fight or screaming argument

31. Declared bankruptcy

32. Forgotten a birthday of someone close to you and did not realize until the next day or later.

33. Been diagnosed with Type 2 diabetes

34. Broke a bone because you fell, slipped, or misstepped 


\section{Appendix E}

\section{Resistance to Sunk Costs Vignettes}

Vignette \#1: "You are buying a gold ring on layaway for someone special. It costs $\$ 200$ and you have already paid $\$ 100$ on it, so you owe another $\$ 100$. One day, you see in the paper that a new jewelry store is selling the same ring for only $\$ 90$ as a special sale, and you can pay for it using layaway. The new store is across the street from the old one. If you decide to get the ring from the new store, you will not be able to get your money back from the old store but you would save $\$ 10$ overall."

Would you be more likely to continue paying at the old store or buy from the new store?

$\begin{array}{llllll}1 & 2 & 3 & 4 & 5 & 6\end{array}$

Most likely to continue paying at the old store
Most likely to buy from the new store

Vignette \#2: "You enjoy playing tennis, but you really love bowling. You just became a member of a tennis club, and of a bowling club, both at the same time. The membership to your tennis club costs $\$ 200$ per year and the membership to your bowling club $\$ 50$ per year. During the first week of both memberships, you develop an elbow injury. It is painful to play either tennis or bowling. Your doctor tells you that the pain will continue for about a year."

Would you be more likely to play tennis or bowling in the next six months?

$\begin{array}{lllllc}1 & 2 & 3 & 4 & 5 & 6 \\ \begin{array}{l}\text { Most likely to } \\ \text { play tennis }\end{array} & & & & & \begin{array}{r}\text { Most likely to } \\ \text { play bowling }\end{array}\end{array}$

Vignette \#3: "You have been looking forward to this year's Halloween party. You have the right cape, the right wig, and the right hat. All week, you have been trying to perfect the outfit by cutting out a large number of tiny stars to glue to the cape and the hat, and you still need to glue them on. On the day of Halloween, you decide that the outfit looks better without all these stars you have worked so hard on."

Would you be more likely to wear the stars or go without?

$$
\begin{array}{llllll}
1 & 2 & 3 & 4 & 5 & 6
\end{array}
$$

Most likely to wear stars
Most likely to not wear stars 
Vignette \#4: "After a large meal at a restaurant, you order a big dessert with chocolate syrup and ice cream. After a few bites you find you are full and you would rather not eat any more of it."

Would you be more likely to eat more or stop eating it?

$$
\begin{array}{llllll}
1 & 2 & 3 & 4 & 5 & 6
\end{array}
$$

$\begin{array}{ll}\text { Most likely to } & \text { Most likely to } \\ \text { eat more } & \text { stop eating }\end{array}$

Vignette \#5: "You are in a hotel room for one night and you have paid \$6.95 to watch a movie on pay TV. Then you discover that there is a movie you would much rather like to see on one of the free cable TV channels. You only have time to watch one of the two movies."

Would you be more likely to watch the movie on pay TV or on the free cable channel?

$\begin{array}{cccccc}1 & 2 & 3 & 4 & 5 & 6 \\ & & & & \\ \begin{array}{l}\text { Most likely to } \\ \text { watch pay TV }\end{array} & & & & \begin{array}{c}\text { Most likely to } \\ \text { watch free cable }\end{array}\end{array}$

Vignette \#6: "You have been asked to give a toast at your friend's wedding. You have worked for hours on this one story about you and your friend taking drivers' education, but you still have some work to do on it. Then you realize that you could finish writing the speech faster if you start over and tell the funnier story about the dance lessons you took together."

Would you be more likely to finish the toast about driving or rewrite it to be about dancing?

$$
\begin{array}{llllll}
1 & 2 & 3 & 4 & 5 & 6
\end{array}
$$

Most likely to write about driving
Most likely to write about dancing

Vignette \#7: "You and your friend are at a movie theater together. Both you and your friend are getting bored with the storyline. You'd hate to waste the money spent on the ticket, but you both feel that you would have a better time at the coffee shop next door. You could sneak out without other people noticing."

Would you be more likely to stay or leave?

$\begin{array}{llllll}1 & 2 & 3 & 4 & 5 & 6\end{array}$

Most likely to stay
Most likely to leave 
Vignette \#8: "You and your friend have driven halfway to a resort. Both you and your friend feel sick. You both feel that you both would have a much better weekend at home. Your friend says it is "too bad" you already drove halfway, because you both would much rather spend the time at home. You agree."

Would you be more likely to drive on or turn back?

$\begin{array}{llllll}1 & 2 & 3 & 4 & 5 & 6\end{array}$
Most likely to
Most likely to
drive on
turn back

Vignette \#9: "You are painting your bedroom with a sponge pattern in your favorite color. It takes a long time to do. After you finish two of the four walls, you realize you would have preferred the solid color instead of the sponge pattern. You have enough paint left over to redo the entire room in the solid color. It would take you the same amount of time as finishing the sponge pattern on the two walls you have left."

Would you be more likely to finish the sponge pattern or to redo the room in the solid color?

$\begin{array}{llllll}1 & 2 & 3 & 4 & 5 & 6\end{array}$

Most likely to finish sponge pattern

Most likely to redo with solid color 


\section{Appendix F}

The Subjective Numeracy Scale

1. How good are you at working with fractions? $(1=$ not at all good, $6=$ extremely good $)$

2. How good are you at working with percentages? (1=not at all good, $6=$ extremely good)

3. How good are you at calculating a $15 \%$ tip? (1=not at all good, $6=$ extremely good)

4. How good are you at figuring out how much a shirt will cost if it is $25 \%$ off? (1=not at all good, $6=$ extremely good)

5. When reading the newspaper, how helpful do you find tables and graphs that are parts of a story? $(1=$ not at all, $6=$ extremely $)$

6. When people tell you the chance of something happening, do you prefer that they use words ("it rarely happens") or numbers ("there's a 1\% chance")? (1=always prefer words, $6=$ always prefer numbers)

7. When you hear a weather forecast, do you prefer predictions using percentages (e.g., "there will be a $20 \%$ chance of rain today") or predictions using only words (e.g., "there is a small chance of rain today"')? (1=always prefer percentages, $6=$ always prefer words)

8. How often do you find numerical information to be useful? ( $1=$ never, $6=$ very often) 


\section{Appendix G}

\section{Demographics Questionnaire}

Young Adults

1. Please indicate your sex: $(\operatorname{sex}) \_$Male ___ Female __ Other

2. Please indicate your marital status:

_ never married

married for ___ years and ___ months

not married, but living together for ___ years and ___ months
widowed/widower, married for ___ years and __ months
divorced, married for ___ years and ___ months
other (please specify __

3. Please indicate your age (in years; e.g. "22")

4. Please indicate your ethnicity: Hispanic or Latino Not Hispanic or Latino Prefer not to answer

5. Please indicate your race: White or Caucasian

Black or African-American

Asian

American Indian or Alaska Native

Native Hawaiian or Other Pacific Islander

Biracial or Multi-racial

Other

Prefer not to answer

6. What is your current employment status?

Employed full time

Employed part time

Partially retired (retired, but working part-time) 
Fully retired (no longer working)

Unemployed

Other (please specify ____ _

7. Please indicate your education (check all that apply):

__ High school diploma or GED

__ Associate's degree

B_ Bachelor's degree

Master's degree

Doctoral degree

8. If you are a college graduate, please indicate which degree(s) you graduated with:

9. How much financial difficulty do you have paying your bills?

a great deal of difficulty

some difficulty

_ a little difficulty

no difficulty

10. Please estimate your gross income from the past 12 months (including wages, social security earnings, tips, etc.)

Less than $\$ 10,000$

$\$ 10,000-19,000$
$\$ 20,000-29,000$
$\$ 30,000-39,000$
$\$ 40,000-49,000$
$\$ 50,000-59,000$
$\$ 60,000-69,000$
$\$ 70,000$ or more
I don't know


11. Please check all that apply: I am currently attending college

I am a college graduate

I did attend college, but did not graduate, and am no longer attending

I have never attended college other (please specify

12. If you are a college student, please indicate your class status:

freshman $/ 1^{\text {st }}$ year sophomore $/ 2^{\text {nd }}$ year

junior $/ 3^{\text {rd }}$ year senior $/ 4^{\text {th }}$ year grad student other (please specify

13. If you are a college student, please indicate your current or intended college major

14. If you are a college student (or a recent graduate), please indicate your GPA

15. If you are a college student (or a recent graduate), please indicate if you have taken any of the following courses:

ACCT 201, 202 Principles of Accounting

ACCT 331 Managerial Accounting

ACCT 431 Cost Management

BADM 623 Graduate level MBA managerial accounting courses BADM 636 Graduate level EMBA managerial accounting courses 
16. If you are a college student (or a recent graduate), who pays for your education? (check all that apply)

_ My parents pay for my education, but I pay for my living expenses My parents pay for my living expenses, but I pay for my education My parents pay for all of my education and living expenses I pay for my all of my education and living expenses I receive scholarships/grants I receive loans I am in the military/ I am attending college under the GI Bill

17. Please estimate your parents' gross income from the past 12 months (including wages, social security earnings, tips, etc.)

Less than $\$ 10,000$

$\$ 10,000-19,000$

$\$ 20,000-29,000$

$\$ 30,000-39,000$

$\$ 40,000-49,000$

$\$ 50,000-59,000$

$\$ 60,000-69,000$

$\$ 70,000$ or more

I don't know

18. How familiar are you with the concept of the sunk-cost fallacy or sunk costs?

$12 \quad 3 \quad 4 \quad 5$

Not at all familiar

Extremely familiar

19. If you indicated that you are at all familiar with the concept of the sunk-cost fallacy or sunk costs, please explain what it is.

Middle-Aged and Older Adults

20. Please indicate your sex: $(\operatorname{sex}) \_$Male __ Female __ Other 
21. Please indicate your marital status:

never married
married for $\_$years and __ months
not married, but living together for ___ years and ___ months
widowed/widower, married for ___ years and ___ months
divorced, married for ___ years and ___ months
other (please specify ___

22. Please indicate your age (in years; e.g. "22")

23. Please indicate your ethnicity: Hispanic or Latino Not Hispanic or Latino Prefer not to answer

24. Please indicate your race: White or Caucasian

B Black or African-American Asian American Indian or Alaska Native Native Hawaiian or Other Pacific Islander Biracial or Multi-racial Other Prefer not to answer

25. What is your current employment status?

__Employed full time Employed part time Partially retired (retired, but working part-time) Fully retired (no longer working) Unemployed Other (please specify ___ _

26. Please indicate your education (check all that apply): High school diploma or GED 


Associate's degree
Bachelor's degree
Master's degree
Doctoral degree

27. If you are a college graduate, please indicate which degree(s) you graduated with:

28. How much financial difficulty do you have paying your bills?

$$
\begin{aligned}
& \text { a great deal of difficulty } \\
& \text { some difficulty } \\
& \text { a little difficulty } \\
& \text { no difficulty }
\end{aligned}
$$

29. Please estimate your gross income from the past 12 months (including wages, social security earnings, tips, etc.)

Less than $\$ 10,000$

$$
\begin{aligned}
& \$ 10,000-19,000 \\
& \$ 20,000-29,000 \\
& \$ 30,000-39,000 \\
& \$ 40,000-49,000 \\
& \$ 50,000-59,000 \\
& \$ 60,000-69,000 \\
& \$ 70,000 \text { or more } \\
& \text { I don’t know }
\end{aligned}
$$

11. Please indicate your current or former occupation

12. If you are currently retired, please estimate the gross annual income you were earning immediately before you retired (including wages, social security earnings, tips, etc.)

Less than $\$ 10,000$

$\$ 10,000-19,000$

\$20,000-29,000 
$\$ 30,000-39,000$

$\$ 40,000-49,000$

$\$ 50,000-59,000$

$\$ 60,000-69,000$

$\$ 70,000$ or more

I don't know

13. How familiar are you with the concept of the sunk-cost fallacy or sunk costs?

$\begin{array}{ccccc}1 & 2 & 3 & 4 & 5 \\ \text { Not at all familiar } & & & & \text { Extremely familiar }\end{array}$

14. If you indicated that you are at all familiar with the concept of the sunk-cost fallacy or sunk costs, please explain what it is. 


\section{Appendix $\mathrm{H}$}

\section{Deleted Items}

You started reading a novel by a best-selling author. You have read 100 pages of the 200 page novel and expect that it will take you about $1 \frac{1}{2}$ months to finish. However, the novel just doesn't seem to be written in a way that grabs your attention. You must decide how many more pages to read to see if the novel improves.

You started reading a novel by a best-selling author. You have read 20 pages of the 200 page novel and expect that it will take you about $1 \frac{1}{2}$ months to finish. However, the novel just doesn't seem to be written in a way that grabs your attention. You must decide how many more pages to read to see if the novel improves.

Think about this situation as you normally would. Which of the following courses of action would you select?

a. stop reading the novel immediately

b. read 25 more pages

c. read 50 more pages

d. read 75 more pages

e. finish reading the novel

You are having computer problems so you call the helpline. You are being charged \$3.99 per minute for the call. You have been on hold for 10 minutes waiting for someone to help you. You must decide how much longer to wait.

You are having computer problems so you call the helpline. You have been on hold for 10 minutes waiting for someone to help you. You must decide how much longer to wait.

Think about this situation as you normally would. Which of the following courses of action would you select?
a. hang up and call back later
b. wait 5 more minutes
c. wait 10 more minutes
d. wait 15 more minutes
e. wait until someone helps you 
You decide to take the bus to work instead of walking as you usually do because you bought a week's worth of bus passes for $\$ 15.99$. Usually it is a 10 minute wait for the bus, but you have been waiting for 20 minutes. The bus ride would be more comfortable than walking. You must decide how much longer to wait for the bus.

You decide to take the bus to work instead of walking as you usually do because you received a week's worth of bus passes for free. Usually it is a 10 minute wait for the bus, but you have been waiting for 20 minutes. The bus ride would be more comfortable than walking. You must decide how much longer to wait for the bus.

Think about this situation as you normally would. Which of the following courses of action would you select?
a. stop waiting and start walking immediately
b. wait for 5 more minutes
c. wait for 10 more minutes
d. wait for 15 more minutes
e. wait until the bus comes 